\title{
Characterizing and Predicting Marine Fog Offshore Newfoundland and Labrador
}

\author{
GEORGE A. ISAAC \\ Weather Impacts Consulting Inc., Barrie, Ontario, Canada \\ Terry Bullock, JenNifer BeAle, And Steven BeAle \\ Wood Environment and Infrastructure Solutions, St. John's, Newfoundland and Labrador, Canada
}

(Manuscript received 28 April 2019, in final form 19 December 2019)

\begin{abstract}
As several review papers have concluded, marine fog is imperfectly characterized, and quantitative visibility forecasts are difficult to produce accurately. Some unique measurements have been made offshore Newfoundland and Labrador of the climatology of occurrence and the microphysical characteristics of marine, or open-ocean, fog. Based on measurements made at an offshore installation over 21 years, the percent of time with visibilities less than $0.5 \mathrm{n}$ mi or approximately $1 \mathrm{~km}(1 \mathrm{n} \mathrm{mi} \approx 1.85 \mathrm{~km})$ reaches $45 \%$ in July, with a low of about $5 \%$ during the winter. The occurrence of fog is mainly due to warm air advection, with the highest frequency occurring with wind directions from over the warm Gulf Stream, and with air temperatures about $2{ }^{\circ} \mathrm{C}$ warmer than the sea surface temperature. There is no diurnal variation in the frequency of occurrence of fog. The microphysical properties of the fog have been documented in the summer time frame, with over $550 \mathrm{~h}$ of in situ measurements made offshore with fog liquid water content greater than $0.005 \mathrm{~g} \mathrm{~m}^{-3}$. The fog droplet number concentration spectra peaks near $6 \mu \mathrm{m}$, with a secondary peak near 25-40 $\mu \mathrm{m}$, which typically contains most of the liquid water content. The median droplet concentration is approximately $70-100 \mathrm{~cm}^{-3}$. The microphysical spectra have been used to develop a new NWP visibility parameterization scheme, and this scheme is compared with other parameterizations currently in use.
\end{abstract}

\section{Introduction}

Marine fog is a hazard to shipping, fishing, oil and gas operations, and search and rescue missions around the world. It can occur frequently as Dorman et al. (2017) have indicated, but it is also difficult to predict as described by Koračin (2017). This paper describes observations made offshore Newfoundland and Labrador in one of the foggiest marine areas (see Dorman et al. 2017). Some unique measurements describing openocean fog have been made and the location of the sites where data were obtained for this paper are shown in Fig. 1.

According to international definitions and the American Meteorological Society (2018), fog is composed of water droplets and reduces visibility to less than $1 \mathrm{~km}$. Normally, air reaches saturation with respect to water in fog. Mist is the name given to reductions in visibility greater than $1 \mathrm{~km}$ and less than $5 \mathrm{~km}$ due to

Corresponding author: George A. Isaac, weatherimpacts@ gmail.com small droplets or wet hygroscopic particles with a relative humidity at $95 \%$ or more. Haze refers to obstructions in visibility not due to activated droplets, and the relative humidity in haze can be less than $95 \%$. The actual definitions vary somewhat and are not precise. In this paper, fog refers to visibility reductions less than several kilometers due to liquid water drops, thus not distinguishing between mist and fog.

The Grand Banks of Newfoundland and Labrador and adjacent areas of the continental shelf are rich in hydrocarbons with the oil-producing Jeanne-D'Arc basin approximately $340 \mathrm{~km}$ east-southeast of St. John's in water depths varying between 80 and $100 \mathrm{~m}$. The Grand Banks is an area with relatively few meteorological and oceanographic measurements. Advection fog is frequent in spring and summer, due to the warm moist air over the Gulf Stream blowing over the colder waters of the Grand Banks, which are cooled by the Labrador Current (Bullock et al. 2016).

A workshop on Metocean Monitoring and Forecasting for the Newfoundland and Labrador Offshore held 22-24 September 2014, identified reduced visibility in 


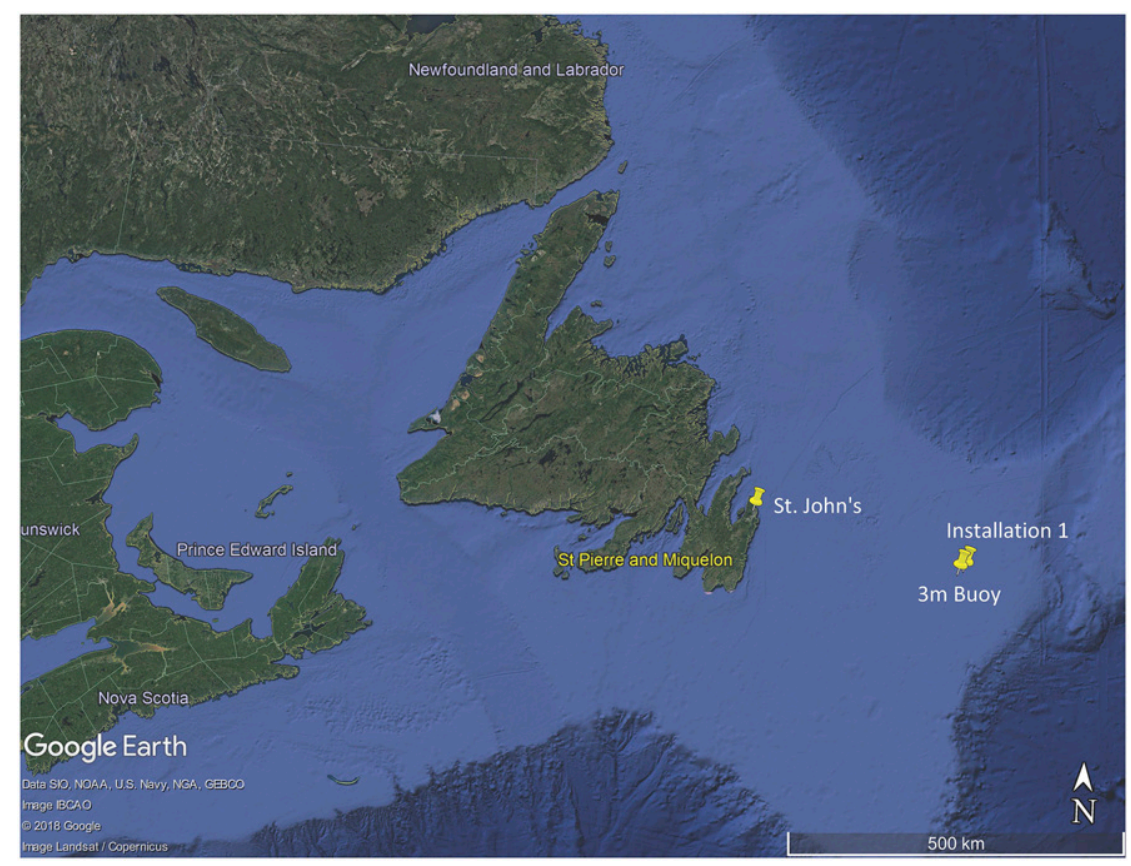

FIG. 1. Map showing the location of the instruments (St. John's, Installation 1, and Marine Institute buoy). Measurements of temperature, dewpoint, relative humidity, visibility, and cloud microphysics (FM-120) were made at $69 \mathrm{~m}$ MSL on Installation 1, while winds were measured at $139 \mathrm{~m}$ MSL. Measurements on the 3-m buoy, from the Marine Institute of Memorial University, are representative of $3 \mathrm{~m}$ MSL. Installation 1 is approximately $300 \mathrm{~km}$ from St. John's, Newfoundland. The 3-m buoy is approximately $10 \mathrm{~km}$ southwest of Installation 1.

fog and high seas as being significant metocean (meteorology and oceanography) issues affecting commercial operations in this area. These issues were confirmed to be highly relevant to offshore operations at a follow-up Harsh Environment Workshop conducted on 31 October 2016. A local helicopter company (J. J. Gerber 2016, personal communication) reported at this 2016 workshop, that in a typical year, hundreds of flights are cancelled due to weather and sea state conditions. As described at the 2014 workshop (L. Coughlan 2016, personal communication), vessel and crane operations are frequently adversely affected by wind, sea state, and visibility conditions.

Transport Canada air regulations state that, although an instrument approach is permitted using onboard radar, the pilot must visually see an offshore helideck at 0.5 nautical miles $(\mathrm{n} \mathrm{mi} ; 1 \mathrm{n} \mathrm{mi} \approx 1.85 \mathrm{~km}$ ) or a missed approach is required. A missed approach means the pilot must not attempt a landing on the helideck, and must either make another attempt or return to shore. This demonstrates that visibility forecasts need to be precise in time, quantitative, and very specific to the location of interest.

Fog offshore the eastern coast of Newfoundland is elegantly described by Scott (1890, p. 120):

"...the density of the fogs on the Banks of Newfoundland is well known, where they are often sharply defined in extent as the hardest looking wool-pack clouds. It is not an uncommon phenomenon, when a fog-bank is lying off the harbour of St. John's, for the bowsprit of a ship to be seen emerging from the fog, while not a trace of the masts or hull is perceptible; and again at times the topmasts will be in bright sunshine while the crew cannot see from stem to stern on deck."

This dense fog has been known to exist since the earliest explorers, and lengthy, circuitous detours were usually taken to avoid the hazardous region (Brodrick 1907). Marcet (1889) is one of the earliest papers which documents fog in the Grand Banks, distinguishing the predominant wind directions for fog along the coast of Newfoundland and over the Grand Banks, with easterly winds along the coast and southerly winds farther out to sea condensing water vapor originating from over the Gulf Stream. Both Marcet (1889) and Willett (1928) are probably the first most in-depth reviews which consider all fog types and occurrences that were known to exist in their time. Scoresby (1822) may be the earliest published material containing measurements taken of fog in the Labrador Sea region, where off the western coast of Greenland he suggested that the fog formed as moist, warm air cooled over ice under a temperature inversion. 

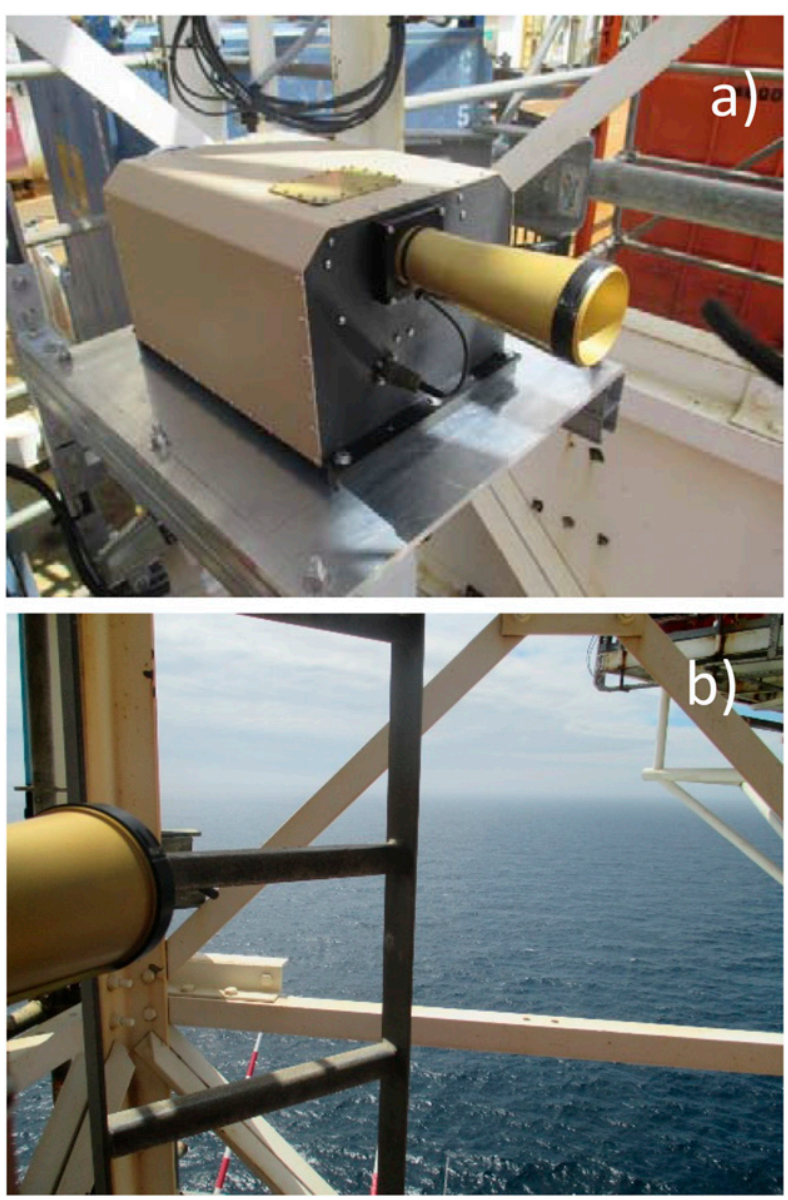

FIG. 2. The (a) FM-120 Fog Monitor on Installation 1 (Fig. 1) and (b) the view from its intake.

In what is perhaps the most definitive study of fog in the region to date, in the summer of 1913, Taylor (1917) spent six months aboard the iceberg scout ship, Scotia, on the Grand Banks. Taylor tied the formation of fog to his theory of turbulence (Taylor 1915) in a Lagrangian framework, making use of data collected from merchant ships. He tracked movement of surface air via the merchant ships and linked them to kite soundings taken aboard the Scotia. The notion of the wind shear that he studied in his previous paper (Taylor 1915) being linked to fog formation is evident as he concludes that cooling at the ocean surface is transferred upward in "vertical currents." Taylor concluded that fog in the area mainly formed as warm air from the Gulf Stream flowed over the cold water of the Grand Banks.

During the 1980s, the Naval Environmental Prediction Research Facility contracted Calspan Corporation to study ocean fog and haze in the North Atlantic, the study of which is presented in Rogers (1989). The work aimed to develop a rule-based forecasting system based on observations of the formation and dissipation of fog and

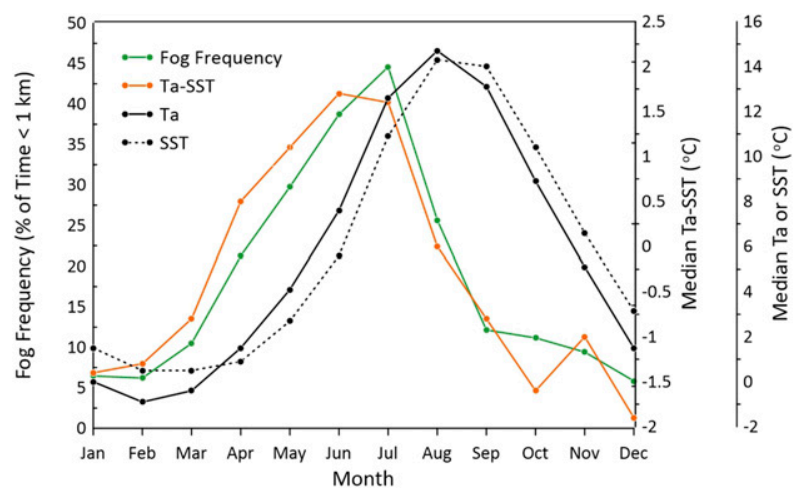

FIG. 3. Plots by month of fog frequency (visibility $<1 \mathrm{~km}$ or about $<0.5 \mathrm{n} \mathrm{mi}$ ), median air temperature (Ta), median sea surface temperature (SST), and the median difference between air temperature and sea surface temperature (Ta - SST). MANMAR data from 1997 to 2017 were used.

haze over the ocean. Of the ten weather ships involved in the collection of data, only two were near the Grand Banks region, one being positioned in the center of the Labrador Sea and the other southeast of the Flemish Cap. During the summer, it was observed that advection fog is more common in the western North Atlantic and inversion fog is more common in the eastern regions.

This paper presents a climatology of the fog, documents its microphysical characteristics, discusses the formation mechanisms in more detail, and suggests a method for producing better forecasts. Very few fixedstation ocean observations exist with measurements other than sea surface temperature (SST), air temperature (Ta), and winds, and most of those are on buoys over shallow water close to land. The over $550 \mathrm{~h}$ of fog in situ cloud microphysical midocean data presented in this paper are unique. Finally, a new forecast scheme is suggested and compared with existing methods.

\section{Data}

Data have been obtained from the platforms indicated in Fig. 1. Manually recorded synoptic marine weather reports, or MANMAR (Environment and Climate Change Canada 2017) were made every $3 \mathrm{~h}$, and those observations from 1997 to 2017 were used in the climatology analysis. The main sensors for the temperature, relative humidity ( $\mathrm{RH})$, and dewpoint observations were located at the helideck at $69 \mathrm{~m}$ above sea level (MSL), where the observer estimated visibility. Fog was defined as observer-reported World Meteorological Organization (WMO) codes 90-93, and the data only include periods with no precipitation (codes 00-49). Precipitation events were excluded to avoid mixing visibility reductions due to rain, and possibly snow, with 


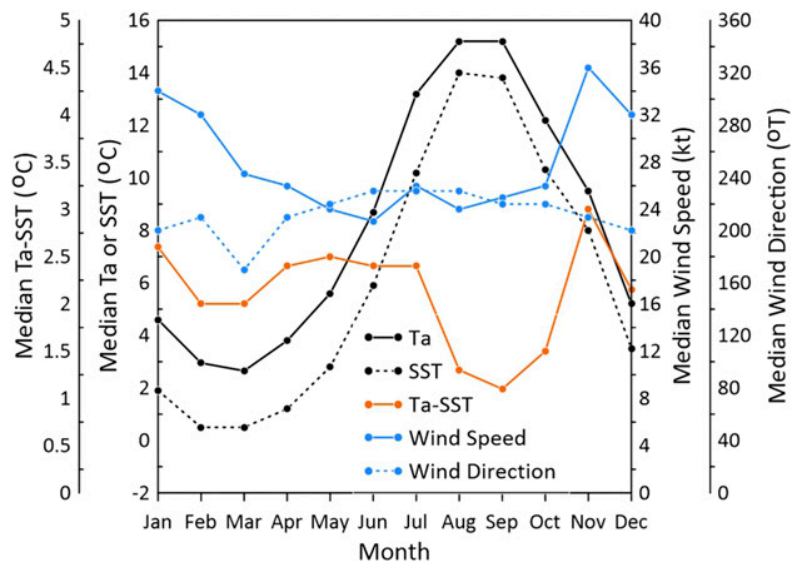

FIG. 4. Plots by month of median Ta, median SST, median Ta - SST, and median wind direction and wind speed during fog events. Data from 1997 to 2017 were used with fog occurrences as defined in Fig. 3. The measurements of Ta were made at $69 \mathrm{~m}$ while winds were measured at $139 \mathrm{~m}$ MSL.

actual fog events. The MANMAR data include 10-min averaged wind measurements made at $139 \mathrm{~m}$ MSL on Installation 1, and 10-min averaged sea surface temperature measurements, with the 10-min averages being made immediately before the report time. The sea surface temperature measurements prior to 2012 were typically vessel water intake measurements (at some 1-m water depth), and the 2012-17 data are from a Mark 4 Datawell Waverider buoy about $3 \mathrm{n}$ mi from Installation 1 .

A Droplet Measurement Technology Fog Monitor (FM-120) was installed on Installation 1 during the fog seasons of 2016, 2017, and 2018 (Fig. 2). The FM-120 was only deployed for a few months each year, and the start and end times varied depending on transportation and technician availability. This instrument measures droplet sizes and concentrations in 30 bins at $1-\mu \mathrm{m}$ intervals from 3 to $14 \mu \mathrm{m}$, and $2-\mu \mathrm{m}$ intervals from 16 to $50 \mu \mathrm{m}$. The instrument also integrates the size distribution to provide fog liquid water content and effective drop diameter, among other parameters. The equipment was calibrated for water droplet size using beads of known sizes both before and after the campaign. The manufacturer's derived concentrations were used and not corrected according the method of Spiegel et al. (2012). The Fog Monitor was installed at a height of $69 \mathrm{~m}$ above sea level on the southwest edge of the platform so that winds and the fog droplets from that most prevalent direction would not have to cross the platform superstructure. Only data collected when the wind direction from the derrick-level anemometer (at $139 \mathrm{~m} \mathrm{MSL}$ ) was from $180^{\circ}$ to $270^{\circ}$ were used in this paper, so the data should not be unduly influenced by the platform. The 1-min data were generally averaged to 10 -min intervals.

A Memorial University Marine Institute 3-m diameter metocean buoy was also used, and it was located about $10 \mathrm{~km}$ southwest of Installation 1 . This buoy was instrumented with an Optical Scientific Incorporated OWI-650 present weather and visibility sensor at $4.5 \mathrm{~m}$ MSL, and air temperature and RH sensors located at $1.4 \mathrm{~m}$ MSL. Data from these sensors, obtained at 1-min intervals, were used.

\section{Climatology}

Figure 3 shows the monthly median Ta and SSTs, visibilities, and air temperature minus sea surface temperature (TSST) at Installation 1, from MANMAR observations and instrument measurements as indicated

TABLE 1. Fog frequency ( $<1 \mathrm{~km}$ or $0.5 \mathrm{n} \mathrm{mi}$ ) in percent of time with no precipitation as a function of time of day (UTC). Sunrise and sunset for the 15th day of the month for the year 2007 is shown. Newfoundland standard time is UTC minus $3.5 \mathrm{~h}$ and Newfoundland daylight time is UTC minus $2.5 \mathrm{~h}$. Data are from MANMAR reports on Installation 1 from 1997 to 2017.

\begin{tabular}{|c|c|c|c|c|c|c|c|c|c|c|c|}
\hline & & \multicolumn{8}{|c|}{ Fog probability $(\%)(<1 \mathrm{~km}$ or $<0.5 \mathrm{n} \mathrm{mi})$ no precipitation } & \multirow{2}{*}{\multicolumn{2}{|c|}{200715 th day }} \\
\hline & & \multicolumn{8}{|c|}{ Time of day (UTC) } & & \\
\hline & & 0000 & 0300 & 0600 & 0900 & 1200 & 1500 & 1800 & 2100 & Sunrise (UTC) & Sunset (UTC) \\
\hline \multirow[t]{12}{*}{ Month } & Jan & 8.1 & 4.1 & 7.2 & 4.5 & 4.9 & 6.2 & 8.0 & 8.2 & 1056 & 1952 \\
\hline & Feb & 7.2 & 5.8 & 6.0 & 6.7 & 8.2 & 6.2 & 3.7 & 6.1 & 1020 & 2038 \\
\hline & Mar & 10.4 & 10.9 & 9.1 & 12.6 & 10.0 & 8.8 & 11.4 & 10.8 & 0930 & 2119 \\
\hline & Apr & 21.5 & 24.1 & 23.0 & 19.4 & 23.0 & 19.5 & 19.5 & 20.1 & 0829 & 2202 \\
\hline & May & 28.4 & 30.8 & 33.5 & 32.0 & 31.1 & 29.6 & 25.9 & 27.1 & 0741 & 2241 \\
\hline & Jun & 39.0 & 39.8 & 38.1 & 45.5 & 36.1 & 35.2 & 37.5 & 38.7 & 0721 & 2310 \\
\hline & Jul & 44.0 & 44.0 & 45.8 & 45.6 & 45.4 & 41.6 & 41.9 & 46.0 & 0736 & 2306 \\
\hline & Aug & 24.9 & 27.8 & 28.7 & 24.7 & 27.4 & 22.0 & 24.0 & 26.0 & 0812 & 2228 \\
\hline & Sep & 11.5 & 14.7 & 12.3 & 12.8 & 11.8 & 11.7 & 10.8 & 10.5 & 0852 & 2129 \\
\hline & Oct & 9.4 & 11.8 & 13.0 & 11.0 & 10.7 & 12.2 & 10.6 & 10.8 & 0932 & 2030 \\
\hline & Nov & 9.7 & 7.3 & 7.7 & 9.6 & 9.6 & 10.3 & 9.9 & 11.1 & 1017 & 1943 \\
\hline & Dec & 4.3 & 5.7 & 6.7 & 6.2 & 5.6 & 6.4 & 4.5 & 7.3 & 1053 & 1927 \\
\hline
\end{tabular}


TABLE 2. Median temperature by month and time of day at Installation 1 with no precipitation present, including times with and without fog. Data are from MANMAR reports from Installation 1 from 1997 to 2017.

\begin{tabular}{crrrrrrrrr}
\hline \hline & \multicolumn{7}{c}{ Median temperature $\left({ }^{\circ} \mathrm{C}\right)$} \\
\cline { 2 - 9 } & & \multicolumn{7}{c}{ Time of day (UTC) } \\
\cline { 2 - 9 } Month Jan & 0.0 & 0.1 & 0.2 & -0.1 & -0.4 & 0.1 & -0.1 & -0.3 \\
& Feb & -0.6 & -0.9 & -1.0 & -0.9 & -0.9 & -0.7 & -0.7 & -1.0 \\
Mar & -0.5 & -0.7 & -0.8 & -0.7 & -0.5 & 0.0 & 0.0 & -0.3 \\
Apr & 1.3 & 1.1 & 1.0 & 1.3 & 1.9 & 1.9 & 2.0 & 1.6 \\
May & 3.9 & 3.8 & 3.6 & 3.6 & 4.1 & 4.6 & 4.6 & 4.4 \\
Jun & 7.3 & 7.2 & 7.1 & 7.1 & 7.9 & 8.0 & 8.2 & 8.0 \\
Jul & 12.7 & 12.4 & 12.3 & 12.2 & 12.6 & 13.1 & 12.9 & 13.0 \\
Aug & 14.6 & 14.3 & 14.2 & 14.2 & 14.6 & 15.1 & 15.2 & 14.9 \\
Sep & 13.0 & 12.9 & 12.6 & 12.6 & 13.1 & 13.4 & 13.6 & 13.3 \\
Oct & 8.6 & 8.9 & 8.6 & 8.4 & 9.0 & 9.2 & 9.5 & 8.9 \\
Nov & 4.9 & 4.9 & 4.9 & 5.0 & 5.1 & 5.6 & 5.5 & 5.1 \\
Dec & 1.3 & 1.5 & 1.5 & 1.5 & 1.5 & 1.6 & 1.5 & 1.3 \\
\hline
\end{tabular}

in section 2. The data include both fog and no-fog events, but hours when precipitation was reported were removed to ensure that the visibility reductions were due solely to fog. The frequency of occurrence of low visibilities $(<1 \mathrm{~km})$ at Installation 1 indicates that fog is most prevalent from May to August, reaching a peak frequency of $45 \%$ in July. A visibility of $1 \mathrm{~km}$ was chosen because helicopters can only approach offshore installations when visibilities are greater than $0.5 \mathrm{n} \mathrm{mi}$ and $1 \mathrm{~km}(\approx 0.54 \mathrm{n} \mathrm{mi})$. Fog events often last several days and cover large areas and, as is described later, most events are caused by warm advection. Figure 3 shows that the frequency of occurrence of fog closely follows the temporal trend of the difference between air temperature and sea surface temperature (Ta - SST), except that the maximum Ta - SST occurs in June while the maximum frequency of fog occurs in July.

Figure 4 shows the monthly median values of Ta, SST, $\mathrm{Ta}$ - SST, wind speed, and wind direction during hours the MANMAR observations indicated that fog $(<1 \mathrm{~km})$ was present. This contrasts with Fig. 3, where both fog and no-fog hours were included. Again, hours with precipitation were excluded. The values of Ta - SST are typically greater than $2^{\circ} \mathrm{C}$, except for August and September where they range between $1^{\circ}$ and $1.5^{\circ} \mathrm{C}$. Monthly median winds in fog are typically from the southwest, with median speeds greater than $20 \mathrm{kt}\left(1 \mathrm{kt} \approx 0.51 \mathrm{~m} \mathrm{~s}^{-1}\right)$.

From December to May, there are days with fog $(<1 \mathrm{~km})$ reported when $\mathrm{Ta}<0^{\circ} \mathrm{C}$. The percentage of fog events with $\mathrm{Ta}<0^{\circ} \mathrm{C}$ are December $(3 \%)$, January (6\%), February (17\%), March (19\%), April (9\%), and May $(5 \%)$. The minimum temperature during these fog cases was $-3^{\circ} \mathrm{C}$, with most events occurring with temperatures closer to $0^{\circ} \mathrm{C}$. It is assumed that all these
TABLE 3. Median sea surface temperature by month and time of day at Installation 1 with no precipitation present, including times with and without fog.

\begin{tabular}{|c|c|c|c|c|c|c|c|c|c|}
\hline & & & & & edian & SST $1^{\circ}$ & & & \\
\hline & & & & & he of $c$ & ay (UT & C) & & \\
\hline & & 0000 & 0300 & 0600 & 0900 & 1200 & 1500 & 1800 & 2100 \\
\hline Month & Jan & 1.6 & 1.5 & 1.5 & 1.5 & 1.5 & 1.5 & 1.5 & 1.5 \\
\hline & Feb & 0.5 & 0.5 & 0.5 & 0.5 & 0.5 & 0.5 & 0.5 & 0.5 \\
\hline & Mar & 0.5 & 0.5 & 0.5 & 0.5 & 0.5 & 0.5 & 0.5 & 0.5 \\
\hline & Apr & 0.9 & 0.9 & 0.9 & 0.9 & 0.9 & 0.9 & 0.9 & 1.0 \\
\hline & May & 2.7 & 2.6 & 2.7 & 2.5 & 2.7 & 2.8 & 2.8 & 2.9 \\
\hline & Jun & 5.6 & 5.6 & 5.6 & 5.6 & 5.6 & 5.8 & 5.9 & 5.8 \\
\hline & Jul & 10.9 & 10.8 & 10.9 & 11.0 & 10.7 & 10.9 & 11.0 & 11.0 \\
\hline & Aug & 14.4 & 14.3 & 14.3 & 14.3 & 14.3 & 14.3 & 14.6 & 14.5 \\
\hline & Sep & 14.0 & 14.0 & 14.0 & 13.9 & 13.9 & 13.9 & 14.0 & 14.0 \\
\hline & Oct & 10.5 & 10.5 & 10.5 & 10.4 & 10.4 & 10.4 & 10.4 & 10.4 \\
\hline & Nov & 6.7 & 6.8 & 6.6 & 6.6 & 6.6 & 6.6 & 6.6 & 6.7 \\
\hline & Dec & 3.2 & 3.3 & 3.2 & 3.2 & 3.1 & 3.1 & 3.2 & 3.1 \\
\hline
\end{tabular}

cases of fog are composed of liquid droplets with a small percentage being supercooled.

Table 1 shows the fog probability $(<1 \mathrm{~km})$ from MANMAR observations as a function of time of day and month. No diurnal variation in fog probability is seen throughout the year. For reference, the sunrise and sunset times for the 15th day of the month during 2007 are shown in Table 1. These times are representative of all years between 1997 and 2017. Tables 2 and 3 show the median Ta and median SST, respectively, for the MANMAR hours as a function of time of day and month. Again, diurnal trends are not present. Since Ta and SST are likely the primary variables in determining fog occurrence, Tables 2 and 3 help explain why there are no diurnal trends in fog frequency (Table 1). Solar radiation does not appear to affect either fog probability, Ta, or SST. This is different from what would be expected for a land or coastal site. (Tardif and Rasmussen 2007; Gultepe et al. 2009), where fog is often more prevalent near sunrise or overnight.

Table 4 shows the median values of Ta, RH, SST, wind speed, and wind direction as a function of MANMAR observation for the month of July, for all times and only hours with fog. July was selected because it is the month with most fog (Fig. 3). Again, there are no diurnal variations in RH or winds for both all the data and foggy periods. The median $\mathrm{RH}$ is high, around $98 \%$ even for all the data, but exceeds $99 \%$ during times with fog. Median wind speeds with fog are in excess of $25 \mathrm{kt}$. Again, the lack of diurnal variations in these important parameters explains the lack of diurnal variation in fog frequency seen in Table 1.

Figure 5 shows the wind speed as a function of wind direction during fog $(<1 \mathrm{~km})$ for the MANMAR hours 
TABLE 4. Median values of Ta, Td, RH, SST, wind speed, and wind direction by time of day using July MANMAR reports from Installation 1 . The data are in two sets: one with all the data and one with data with fog $(<1 \mathrm{~km})$ reported.

\begin{tabular}{|c|c|c|c|c|c|c|c|c|c|}
\hline & & \multicolumn{8}{|c|}{ Time of day (UTC) } \\
\hline & & 0000 & 0300 & 0600 & 0900 & 1200 & 1500 & 1800 & 2100 \\
\hline & & \multicolumn{8}{|c|}{ July 1997-2017 } \\
\hline \multirow[t]{6}{*}{ Parameter } & $\mathrm{Ta}\left({ }^{\circ} \mathrm{C}\right)$ & 12.7 & 12.4 & 12.3 & 12.2 & 12.6 & 13.1 & 12.9 & 13.0 \\
\hline & RH (\%) & 98.0 & 98.0 & 98.7 & 98.0 & 98.0 & 98.0 & 97.4 & 98.0 \\
\hline & $\operatorname{SST}\left({ }^{\circ} \mathrm{C}\right)$ & 10.9 & 10.8 & 10.9 & 11.0 & 10.7 & 10.9 & 11.0 & 11.0 \\
\hline & Wind speed (kt) & 21 & 22 & 22 & 22 & 21 & 22 & 21.5 & 23 \\
\hline & Wind direction $\left({ }^{\circ} \mathrm{T}\right)$ & 230 & 230 & 230 & 230 & 230 & 230 & 230 & 230 \\
\hline & & \multicolumn{8}{|c|}{ July with fog 1997-2017 } \\
\hline \multirow[t]{5}{*}{ Parameter } & $\mathrm{Ta}\left({ }^{\circ} \mathrm{C}\right)$ & 13.3 & 13.0 & 13.1 & 13.1 & 13.0 & 13.4 & 13.2 & 13.5 \\
\hline & RH (\%) & 99.3 & 99.3 & 99.3 & 99.3 & 99.3 & 99.3 & 99.3 & 99.3 \\
\hline & $\operatorname{SST}\left({ }^{\circ} \mathrm{C}\right)$ & 10.4 & 10.3 & 10.1 & 10.6 & 10.0 & 10.1 & 10.0 & 10.7 \\
\hline & Wind speed (kt) & 25 & 23.5 & 25 & 26 & 26.5 & 27 & 26 & 27 \\
\hline & Wind direction $\left({ }^{\circ} \mathrm{T}\right)$ & 230 & 230 & 230 & 230 & 230 & 230 & 230 & 230 \\
\hline
\end{tabular}

in July. Typically, winds are from the southwest when fog is present, which can also be concluded from the data in Fig. 4 and Table 4. However, Fig. 5 also shows that fog can be present with winds in excess of $50 \mathrm{kt}$.

It is useful to characterize sea fog based upon the Ta - SST (TSST) difference. Under warm air advection, the air temperature is greater than the SST and TSST $>0$, whereas with cold air advection, the air temperature is less than the SST and TSST $<0$. Figure 6 shows that warm advection fog observations account for roughly $75 \%$ of the MANMAR fog observations, and cold advection fog observations account for roughly $25 \%$. Some of the fog observations may be due to stratus lowering fog, not cold and warm advection. However, it is assumed that stratus lowering fog does not often occur. It would be difficult to characterize this fog type without doing a full model or observational study following parcels of potential fog forming air masses for each case. Taylor (1917) also found that advection of warm air over cold water was the dominate fog formation mechanism.

Figure 7 shows the air temperature (Ta) and dewpoint (Td) minus the SST as a function of visibility from Installation 1 using the MANMAR data. The lowest visibilities occur with the highest air or dewpoint temperature minus SST values. However, given the large scatter, it would be difficult to create a parameterization using these data. Figure $7 \mathrm{~b}$ was added because Osborne (1976) suggested that Td - SST was a good predictor of fog occurrence over the Scotia Shelf. Comparing Figs. 7a and $7 \mathrm{~b}$, there is no evidence that replacing Ta with $\mathrm{Td}$ is an improvement.

Vertical profiles were collected in 2018 using rawinsondes and tethered balloons. Figure 8 shows rawinsonde profiles on 19 and 29 July 2018 made using a Vaisala Sounding System (MW41) deployed from an offshore support vessel. The profiles clearly show warm air above the colder ocean surface with southwest winds, which is consistent with summaries of data given previously. The profiles show how rapidly the air becomes saturated above the colder ocean surface with fog depths reaching hundreds of meters. This agrees with the early sounding data of Taylor (1917).

Published works have also referred to warm advection fog as advection cooling fog and cold sea fog, since the air temperature is cooled below the dewpoint temperature within the fog. Warm advection fog is also the most frequent type in the Yellow Sea with a peak occurrence in June, no diurnal dependence, and an average lifetime of $62 \mathrm{~h}$ (Kim and Yum 2010). The North Sea off the northeast coast of Scotland (Findlater et al. 1989), the South China Sea (Huang et al. 2011; Huang et al. 2015), and the U.S. West Coast (Pilié et al. 1979; Leipper 1994;

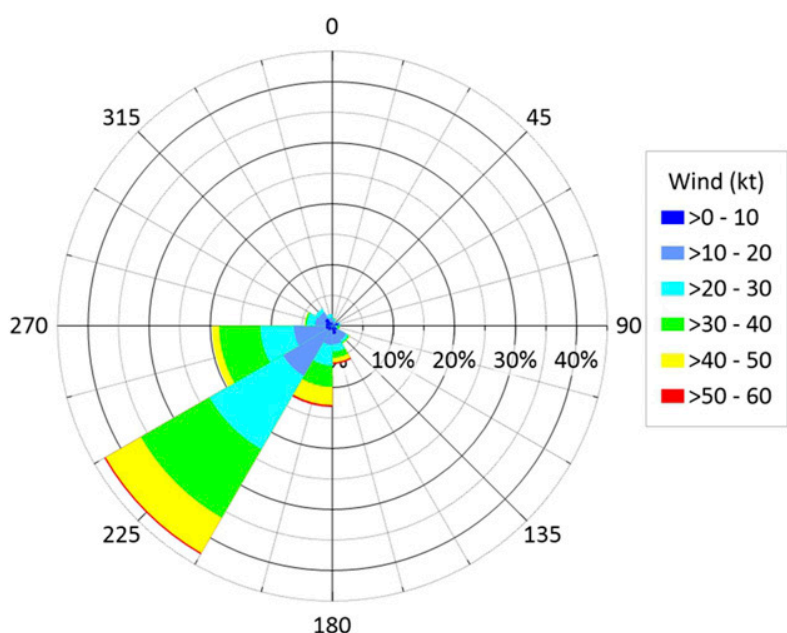

FIG. 5. July (1997-2017) wind speeds as a function of wind direction during fog $(<1 \mathrm{~km})$ as defined in Fig. 2. 


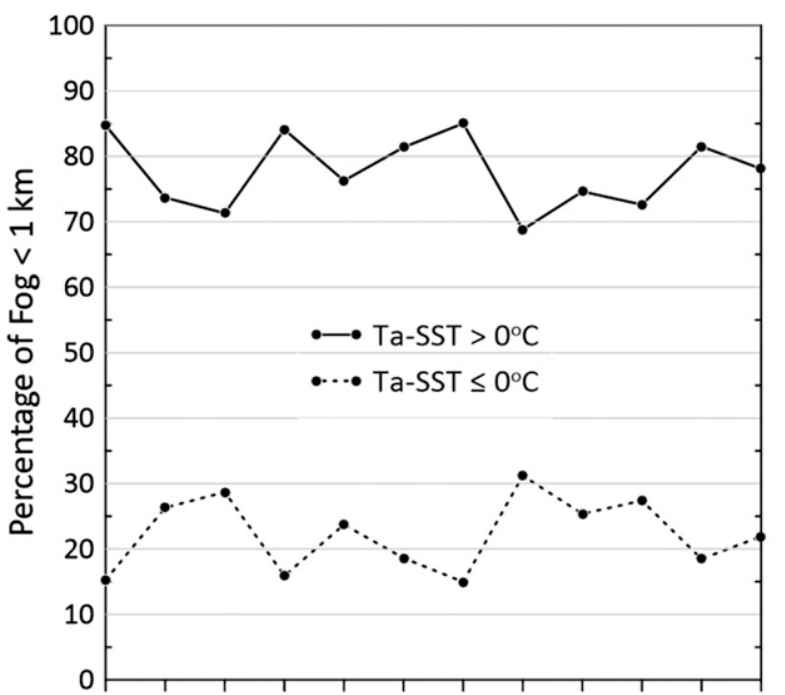

Jan Feb Mar Apr May Jun Jul Aug Sep Oct Nov Dec Month

FIG. 6. Fraction of warm advection $\left(\mathrm{Ta}-\mathrm{SST}>0^{\circ} \mathrm{C}\right)$ and cold advection (Ta $\left.-\mathrm{SST} \leq 0^{\circ} \mathrm{C}\right)$ fog observations. Fog (visibility $<1 \mathrm{~km}$ ) was defined as in Fig. 3. MANMAR data from 1997 to 2017 were used.

Lewis et al. 2004) are also prone to warm advection fog. The North Sea, South China Sea, and U.S. West Coast warm advection fogs have exhibited diurnal modulation, while those in the Yellow Sea (which is more geographically similar to the Grand Banks, given the proximate location of major warm and cold ocean surface currents) have not. With an abrupt onset of sea fog occurrence in April and an abrupt termination in August (Zhang et al. 2009), the highest occurrence of sea fog in the Yellow Sea is in July. The July maximum of sea fog frequency coincides with the maximum difference between the air temperature and the SST that occurs due to the tidal mixing in the ocean surface layer above the strong tidal currents that are generated as water flows from the outer ocean over the shallower shelf, and interacts with the sea floor topography (Cho et al. 2000).

As warm, moist air flows over a colder sea surface, turbulent heat transfer to the sea surface cools the air and haze droplets form as the air temperature is lowered toward its dewpoint temperature. Gao et al. (2007) find that an air temperature minus SST difference between $0^{\circ}$ and $4^{\circ} \mathrm{C}$ is conducive to fog formation in the Yellow Sea, while higher temperature differences under strong temperature inversions are not suitable. Likewise, Guo et al. (2015) find a $4^{\circ} \mathrm{C}$ difference at fog onset and Kim and Yum (2010) find the average difference of all events between 2002 and 2006 is roughly $4^{\circ} \mathrm{C}$. In the South China Sea, the average air-sea temperature difference was roughly $2^{\circ} \mathrm{C}$ and ranged between approximately $1^{\circ}$ and $4^{\circ} \mathrm{C}$ during one observed warm advection fog event (Huang et al. 2015). There are many similarities between the earlier reported works and this paper, but the

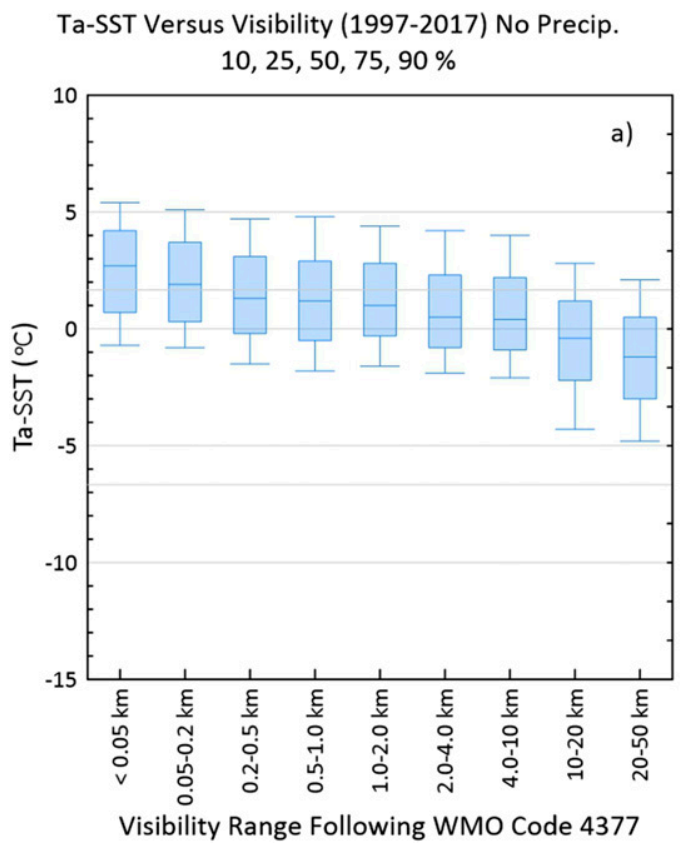

Td-SST Versus Visibility (1997-2017) No Precip. $10,25,50,75,90 \%$

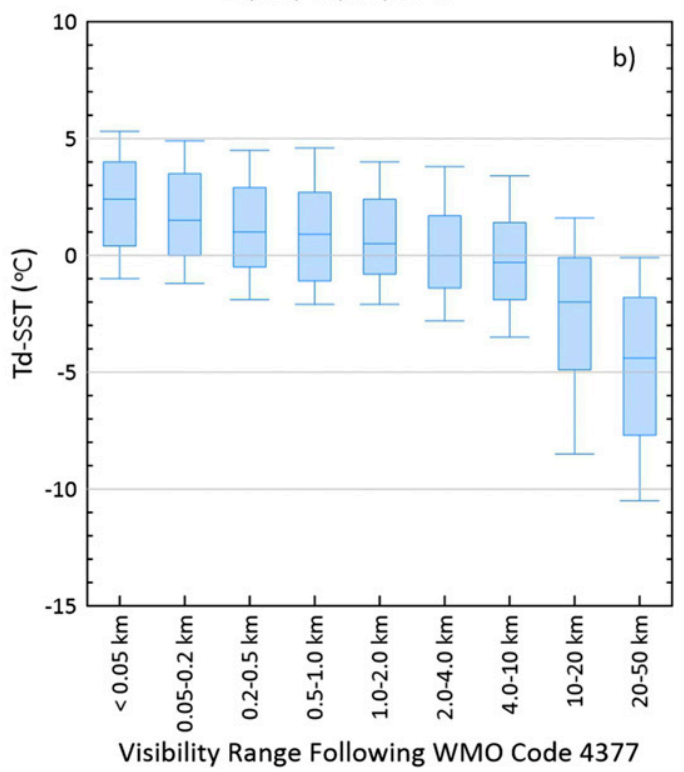

FIG. 7. The (a) Ta minus sea surface temperature (SST) vs visibility and (b) dewpoint (Td) minus SST vs visibility. The bars represent the 10th, 25 th, 50th, 75 th, and 90th percentile values with the shaded area between the 25th and 75 th percentile values. 

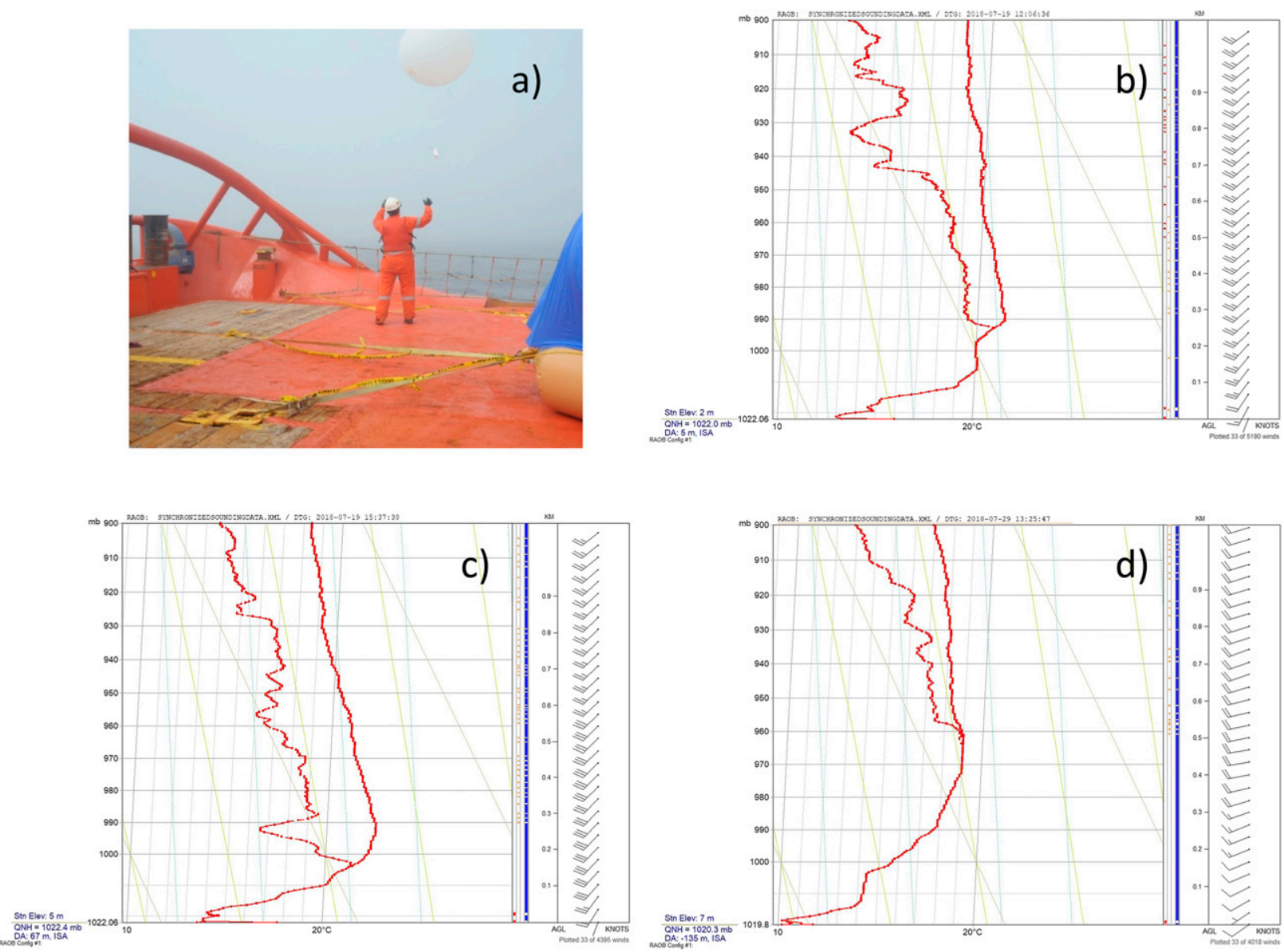

FIG. 8. Examples of rawinsonde releases in skew $T-\log p$ format from (a) an offshore support vessel. The soundings at (b) 1206 and (c) 1537 UTC $19 \mathrm{Jul} 2018$ were made at $46.27^{\circ} \mathrm{N}, 49.00^{\circ} \mathrm{W}$ in a fog layer that ranged from 175 to $250 \mathrm{~m}$ in depth with winds from 20 to $30 \mathrm{kt}$, approximately from the southwest. A sounding from a balloon released at (d) $1325 \mathrm{UTC} 29 \mathrm{Jul} 2018$ at $47.22^{\circ} \mathrm{N}, 48.65^{\circ} \mathrm{W}$ is shown, where the fog layer extends to about $500 \mathrm{~m}$, with the surface-level horizontal visibility being reported as $250 \mathrm{~m}$ at the time of release.

observations presented here are unique in that they are from an open-ocean area, not coastal areas, where most, if not all, of the above studies were performed.

\section{Microphysics}

To understand how the fog droplet size distribution impacts visibility, a summary of the relevant relationships for daytime visibility $V_{k}$, extinction coefficient $\beta$, and liquid water content (LWC) are given below:

$$
\begin{aligned}
V_{k} & =\frac{-\ln (\varepsilon)}{\beta}, \\
\beta & =\frac{3 \mathrm{LWC}}{\rho_{w} D_{\text {eff }}}, \\
\mathrm{LWC} & =\rho_{w} N \frac{\pi}{6} D_{\mathrm{eff}}^{3}, \quad \text { and }
\end{aligned}
$$

$$
V_{k}=\frac{1.24 \rho_{w}^{2 / 3}}{\operatorname{LWC}^{2 / 3} N^{1 / 3}}
$$

where $\varepsilon$ is the contrast threshold, $\rho_{w}$ is the density of water, $D_{\text {eff }}$ is the effective drop diameter, and $N$ represents the droplet number concentration.

Equation (1) is the basic relationship between visibility and extinction as described by Koschmieder (1924). A contrast threshold of 0.05 is the value recommended by the WMO (Boudala et al. 2012). A description of how Eqs. (2) and (3) are derived can be found in Korolev et al. (2001). Equation (4) is derived from Eqs. (1)-(3) using 0.05 as the contrast threshold.

If two of the three parameters, LWC, $N$, and $D_{\text {eff }}$, are known, assuming the fog droplets are spherical, then the daytime visibility can be calculated. Since the Fog Monitor measures all three parameters, visibility can be calculated from its measurements. Nighttime visibility is 
determined somewhat differently and is dependent on the ambient light and "landing light aids" and is described in more detail by Boudala et al. (2012). Since helicopters do not operate at night offshore Newfoundland and Labrador, nighttime visibility is not calculated. However, the climatology and the cloud microphysical measurements include observations made at night. The daytime visibility definition is used as in Eq. (1) for nighttime observations.

Figure 9 shows a typical example of the Fog Monitor FM-120 averaged fog droplet size distribution from 0900 to 0905 UTC 28 July 2016. The number distribution is bimodal with a dominant peak near $5 \mu \mathrm{m}$ and a secondary peak between 30 and $40 \mu \mathrm{m}$. The liquid water content distribution shows that most of the liquid is in the larger droplet sizes, so that secondary peak in number concentration is very important in determining visibility. As Eq. (4) shows, visibility is primarily determined by the liquid water content of the fog.

Figure 10 shows histograms of the 10 -min-averaged droplet number concentration for periods when the liquid water content was greater than $0.005 \mathrm{~g} \mathrm{~m}^{-3}$ during 2016 (Fig. 10a), 2017 (Fig. 10b), and 2018 (Fig. 10c). The histograms are relatively broad with median droplet concentrations of 75,97 , and $69 \mathrm{~cm}^{-3}$ with median liquid water contents of $0.049,0.057$, and $0.057 \mathrm{~g} \mathrm{~m}^{-3}$ for 2016 , 2017, and 2018, respectively. The similarity of the measurements for the 3 years is striking. Although not shown, the droplet concentration does not appear to be related to liquid water content. If such a relationship existed, it would have been useful for a model parameterization.

As the wind speed increases, transfer of aerosol salt particles from the ocean surface should increase, and this could increase the droplet concentration. However, Fig. 11 shows that there is no relationship between wind speed at the $139 \mathrm{~m}$ tower height and droplet concentration for the measurements made in 2016, 2017, and 2018. This is unfortunate, because it would be useful to relate droplet concentration to wind speed in any modeldeveloped parameterization.

Figure 12 displays the liquid water content as a function of droplet size and liquid water content intervals of $0.005-0.01,0.01-0.05,0.05-0.1$, and greater than $0.1 \mathrm{~g} \mathrm{~m}^{-3}$ for 2016 (Fig. 12a), 2017 (Fig. 12b), and 2018 (Fig. 12c). As the liquid water content increases, more water content appears in the second mode of droplet concentration, as shown in Fig. 9, while the amount of liquid in the first mode remains relatively constant. It is plausible that the additional liquid water content, transferred from the ocean surface, goes into the larger drop sizes.

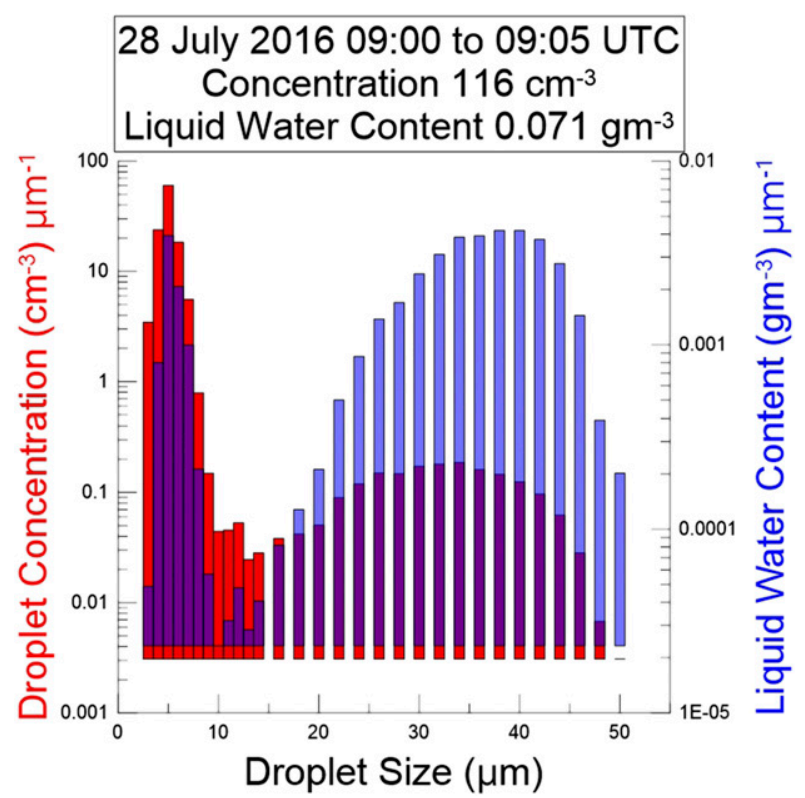

FIG. 9. An example of the droplet size distribution as measured by the FM 120 Fog Monitor. The red and blue bars are for droplet concentration and liquid water content, respectively. Where the red and blue bars overlap, the color changes to a mix of red and blue.

Tomasi and Tampieri (1976), in a theoretical study, concluded that the extinction coefficient was related to LWC $^{-2 / 3}$. Papers by Houghton (1939), Eldridge (1966, 1971), and Pinnick et al. (1978) reached the same conclusion using observations. Equation (4), which is derived using Eqs. (1)-(3), shows that visibility is related to $\mathrm{LWC}^{-2 / 3}$. The proportionality constant in such a relationship would depend on the droplet number concentration $\left(N^{-1 / 3}\right)$.

There are few observations of the fog droplet number concentration reported by other authors. Kunkel (1984) showed the daily mean concentration of fog droplets $>$ $2.5 \mu \mathrm{m}$ to be about $230 \mathrm{~cm}^{-3}$ at $30 \mathrm{~m}$ and $65 \mathrm{~cm}^{-3}$ at $5-\mathrm{m}$ elevation, with the mean liquid water content being 0.17 and $0.07 \mathrm{~g} \mathrm{~m}^{-3}$ at 30 and $5 \mathrm{~m}$, respectively. Pinnick et al. (1978) also show that the liquid water content in fogs increases with altitude from the surface to $150 \mathrm{~m}$, for their measurements made during several days in West Germany using a tethered balloon. Zhao et al. (2013) found mean values of droplet number concentration of $54 \mathrm{~cm}^{-3}$ and LWC of $0.021 \mathrm{~g} \mathrm{~m}^{-3}$ for near-surface measurements made in sea fog on the east coast of Leizhou Peninsula, China. The measurements of Kunkel and Zhao et al. are representative of coastal fog and perhaps the best comparison available to the results presented in this paper. There are substantial differences between the studies in droplet number concentration and liquid water content, although the reasons are unclear. However, 


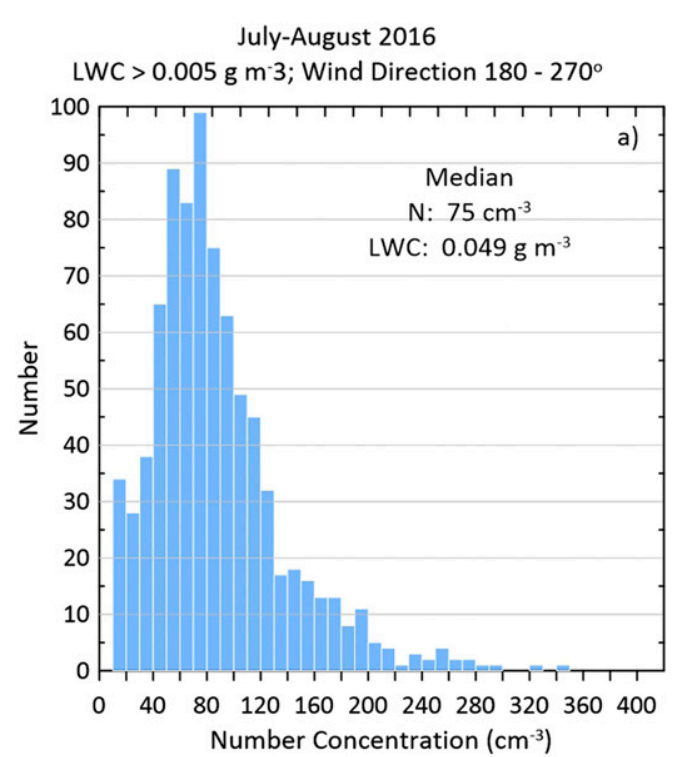

June, July 2018

LWC $>0.005 \mathrm{~g} \mathrm{~m}^{-3}$; Wind Direction $180-270^{\circ}$

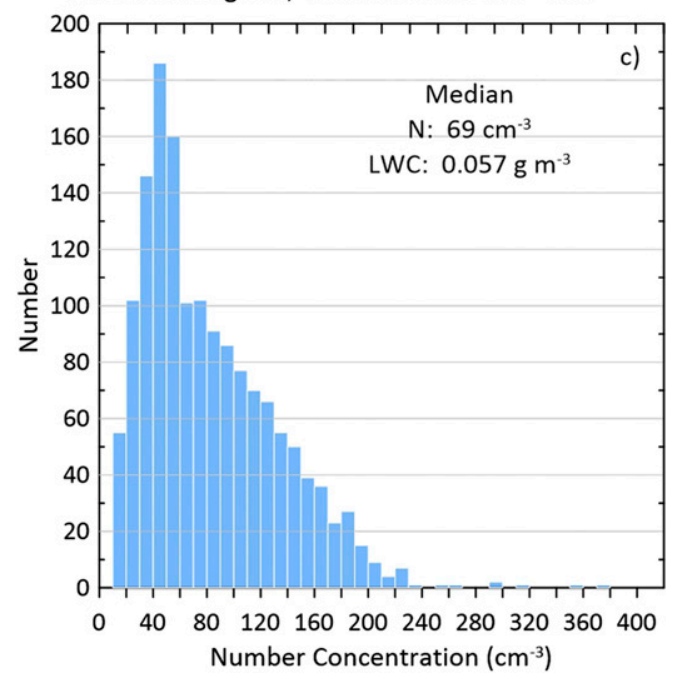

from the above references, vertical variations in fog microphysics can be significant.

\section{Currently used parameterizations and comparisons using 2016, 2017, and 2018 data}

Currently, prediction of visibility in numerical weather prediction (NWP) models is mainly done through parameterizations such as Stoelinga and Warner (1999), Gultepe and Milbrandt (2010), and Boudala et al. (2012). Recently, 1D ultrafine resolution models such as the Code de Brouillard á l'Echelle Locale (COBEL) model (Bergot and Guedalia 1994), and the Parameterized FOG (PAFOG) model (Bott and Trautmann 2002), have been embedded in $3 \mathrm{D}$ numerical weather prediction models.
June - August 2017

LWC $>0.005 \mathrm{~g} \mathrm{~cm}^{-3}$; Wind Direction $180-270^{\circ}$

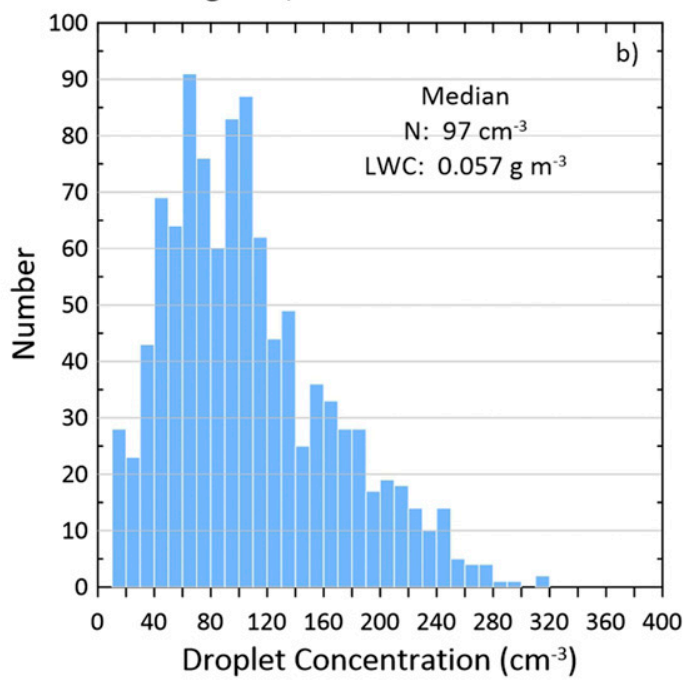

FIG. 10. Histograms of droplet number concentration with liquid water content greater than $0.005 \mathrm{~g} \mathrm{~m}^{-3}$, for measurements made with the FM-120 during (a) 2016, (b) 2017, and (c) 2018. The data were averaged in 10-min blocks, and the graphs represent 143,176 , and $257 \mathrm{~h}$ of observations in 2016, 2017, and 2018, respectively.
Kim and Yum (2012) used a WRF-PAFOG coupling to investigate the formation of cold-advection fog in the Yellow Sea and found that the coupled model simulates the advection fog better compared to the uncoupled WRF model. Wilkinson et al. (2013) used a scheme to predict both droplet number concentration and cloud liquid water content and thus visibility. There have been rule-based methods for fog prediction (Burrows and Toth 2011) as well as conditional climatology or fuzzy logic methods based on climate data (Hansen 2007). A more complete review of all the modeling techniques can be found in Koračin (2017). This section emphasizes the parameterizations of Stoelinga and Warner (1999), Gultepe et al. (2006, 2010), and Boudala et al. (2012). 
Droplet Concentration Versus Wind Speed (2016) LWC $>0.005 \mathrm{~g} \mathrm{~m}^{-3}$; Wind Direction $180-270^{\circ}$

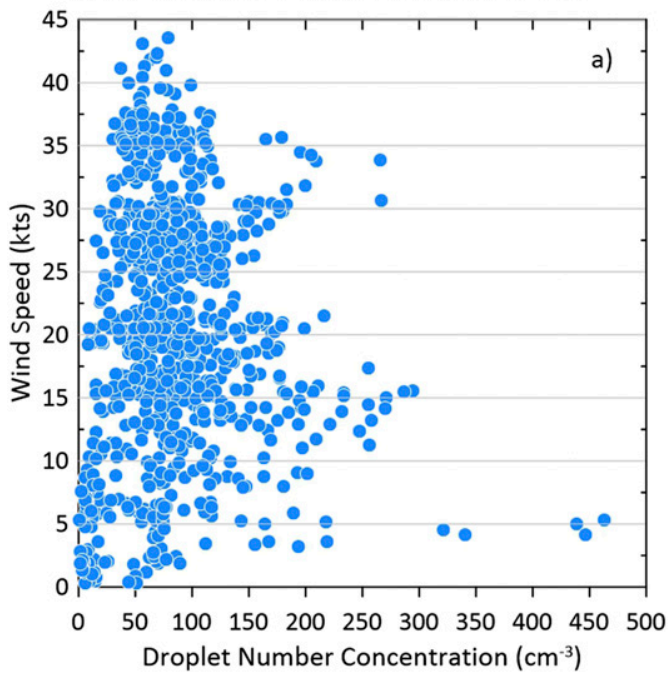

Droplet Concentration Versus Wind Speed (2018) LWC $>0.005 \mathrm{~g} \mathrm{~m}^{-3}$; Wind Direction $180-270^{\circ}$

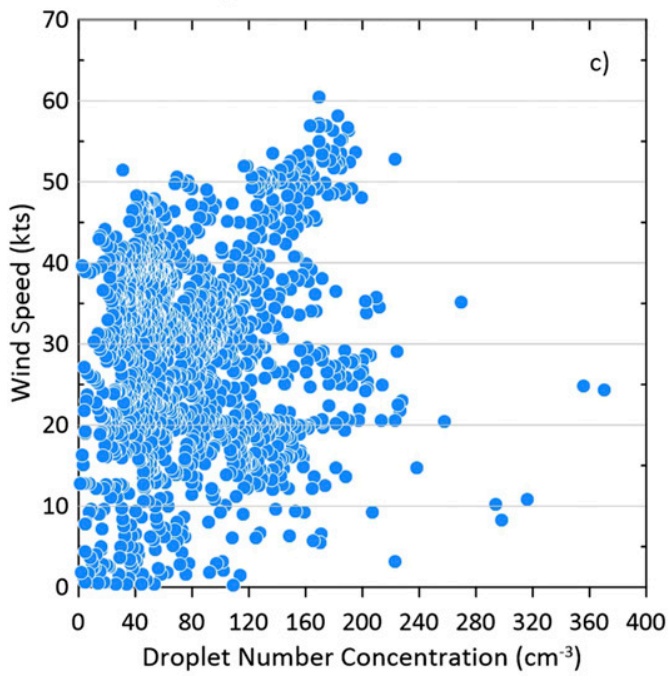

Boudala et al. (2012) proposed a method for predicting visibility in fog based mainly on relative humidity (RH), with the ratio of dewpoint to air temperature having some influence [see their Eq. (8)]. Once RH reached a certain value ( $97 \%$ or $98 \%$ ), lower visibilities were possible, and the visibility decreased as $\mathrm{RH}$ approached $100 \%$. The measurements used to determine the parameterization were obtained at Toronto International Airport (CYYZ), where radiation fog was likely the dominant fog type present.

To test the relationship between visibility and $\mathrm{RH}$, data from Installation 1 were analyzed. Figure 13 shows relevant MANMAR observations from Installation 1 from 1997 to 2017 (Fig. 13a) as well as measurements
Droplet Concentration Versus Wind Speed (2017) LWC $>0.005 \mathrm{~g} \mathrm{~m}^{-3}$; Wind Direction $180-270^{\circ}$

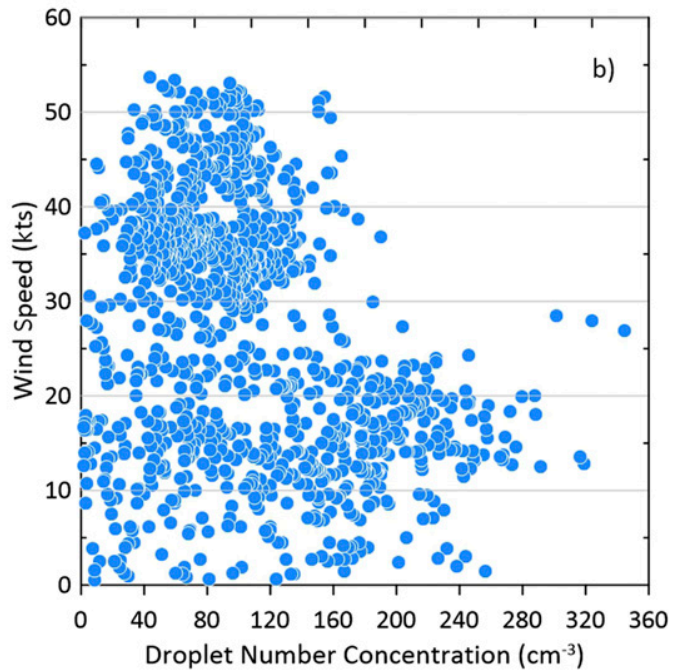

FIG. 11. Droplet concentration vs wind speed for (a) 2016, (b) 2017, and (c) 2018 for the same dataset as in Fig. 10. from the Marine Institute of Memorial University instrumented 3-m diameter metocean buoy (Fig. 13b). Both sets of data show no clear relationship between $\mathrm{RH}$ and visibility in the critical range with visibilities $<2-3 \mathrm{~km}$. It would not be possible to diagnose a quantitative value of visibility between 1 and $2 \mathrm{~km}$ using $\mathrm{RH}$ alone. This agrees with the analysis of Korolev and Isaac (2006), who showed that the RH in a liquid cloud rapidly approaches $100 \%$ whenever cloud droplets were present, unless strong vertical motions were also present. This creates some doubt as to why the fog prediction scheme of Boudala et al. (2012) should have any value, but this issue is discussed in more detail later. 

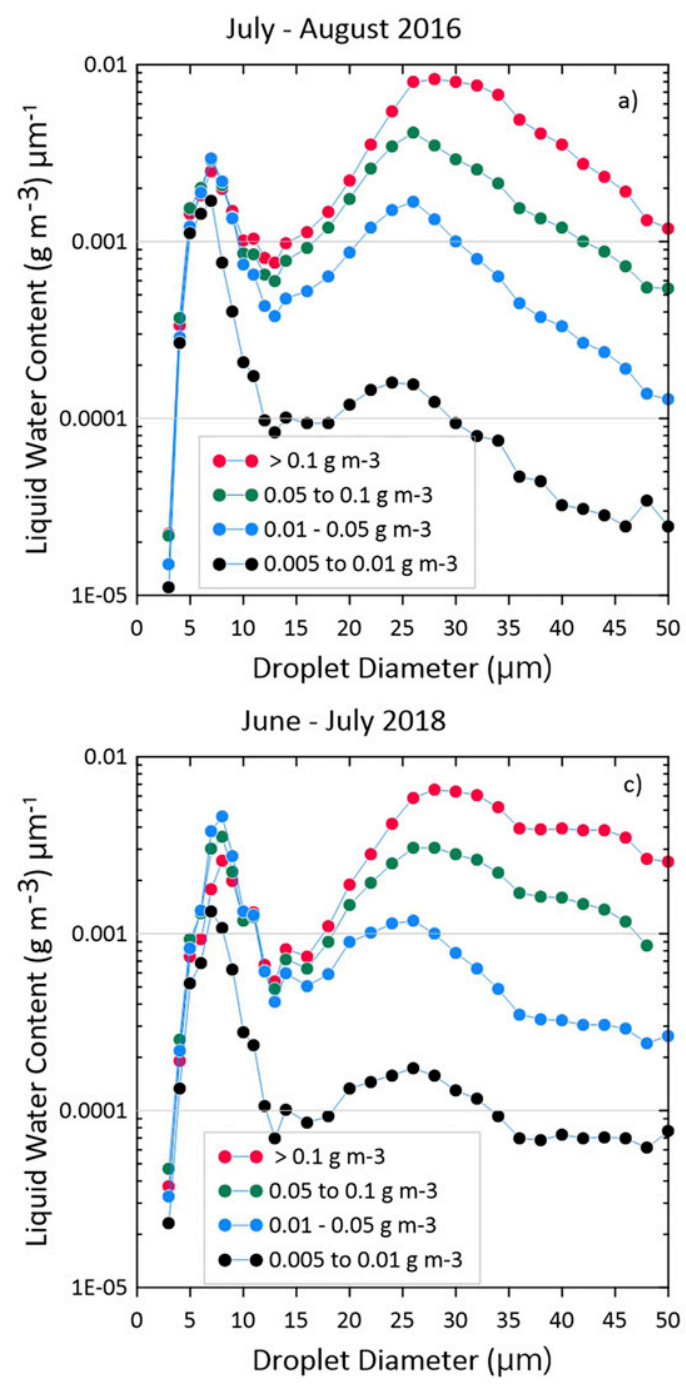

Gultepe et al. (2006 and 2010) devised visibility (denoted Vis) parameterizations that are a function of $1 /\left(\right.$ LWC $\left.\times N_{d}\right)$, where $N_{d}$ represents the droplet concentration. The 2006 paper [ $\mathrm{Vis}=1.002 /\left(\mathrm{LWC} \times N_{d}\right)^{0.6473}$ ] used aircraft-based measurements in stratus clouds obtained during a project off Yarmouth, Nova Scotia. The measurements were not actually made in fog. The 2010 paper $\left[\mathrm{Vis}=0.8771 /\left(\mathrm{LWC} \times N_{d}\right)^{0.49034}\right.$ ] used FM-100 sensor data (an earlier version of the FM-120) from one day (27 June 2006) at a coastal site in Lunenburg, Nova Scotia. These two parameterizations are plotted in Fig. 14 against the 2016 (Fig. 14a), 2017 (Fig. 14b), and 2018 (Fig. 14c) The FM-120 10-min data were obtained offshore. The Gultepe et al. parameterizations fit the 2016, 2017, and 2018 data reasonably well, but there are substantial differences. However, if one examines the equations shown in section 3, visibility should depend on LWC to the two-thirds

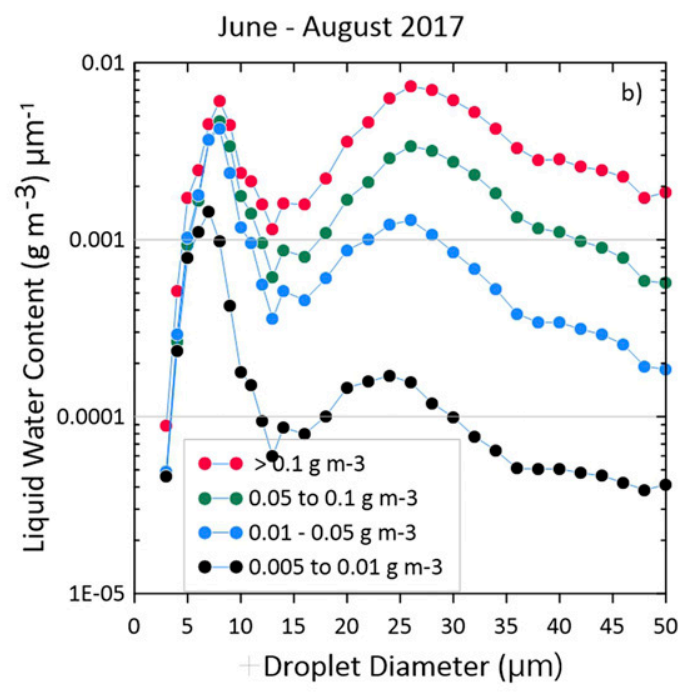

FIG. 12. Liquid water content vs droplet diameter for LWC ranges of 0.005-0.01, 0.01-0.05, 0.05-0.1, and greater than $0.1 \mathrm{~g} \mathrm{~m}^{-3}$ for (a) 2016, (b) 2017, and (c) 2018 . power and droplet concentration to the one-third power [see Eq. (4)].

The Stoelinga and Warner (1999) fog prediction scheme is widely used in U.S. NWP models and is based on the measurements made by Kunkel (1984), who related cloud liquid water content to the extinction coefficient $\beta$. The measurements of Kunkel (1984) were made $12 \mathrm{~km}$ inland from the south shore of Cape Cod, Massachusetts, and were representative of $90 \mathrm{~h}$ in advection fog.

Figure 15a compares the 2016, 2017, and 2018 Fog Monitor 10-min averages of measured extinction coefficient against the measured liquid water content. Also shown is the fit that Kunkel (1984) presented in his paper. The equations for the fits are presented in Table 5 . Since Kunkel used liquid water content values greater than $0.018 \mathrm{~g} \mathrm{~m}^{-3}$, fits were done using that threshold and $0.005 \mathrm{~g} \mathrm{~m}^{-3}$. Figure $15 \mathrm{a}$ shows significant visibility 
RH Versus WMO Code 4377 (1997-2017) No Precip. $10,25,50,75,90 \%$

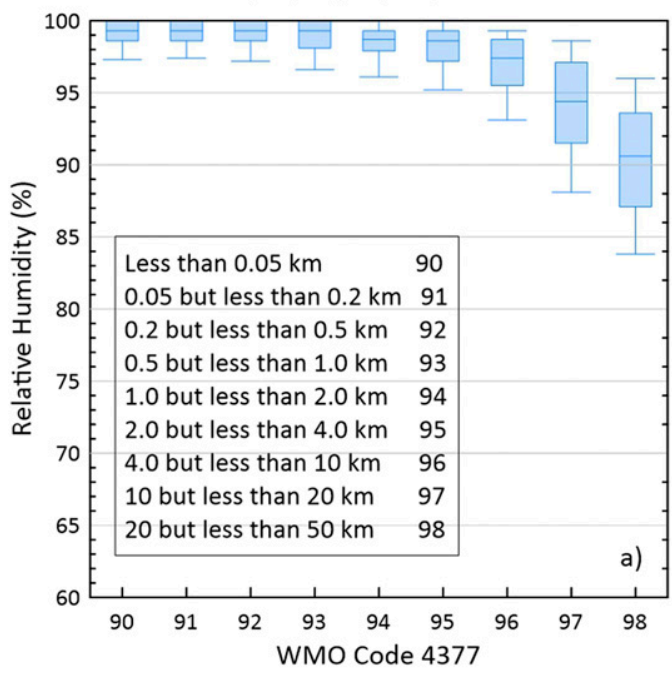

Buoy RH Versus Visibility July \& August 2016 No Precip. $10,25,50,75,90 \%$

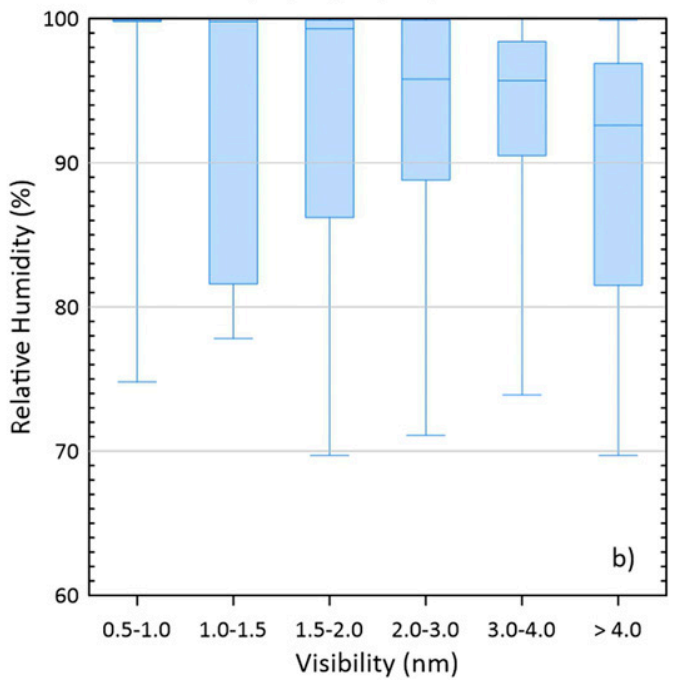

FIG. 13. (a) Visibility (WMO code 4377) vs relative humidity (RH) using MANMAR observations from Installation 1 for 1997-2017 and (b) visibility vs RH using buoy measurements as located in Fig. 1 from July and August 2016. The buoy was provided and instrumented by the Marine Institute of Memorial University of Newfoundland. Percentile values are shown as in Fig. 7.

reductions occur even with liquid water contents less than $0.018 \mathrm{gm}^{-3}$ and greater than $0.005 \mathrm{~g} \mathrm{~m}^{-3}$. Figure $15 \mathrm{~b}$ indicates the $0.005 \mathrm{~g} \mathrm{~m}^{-3}$ limit fits of visibility versus liquid water content with the contrast threshold of 0.02 used by Kunkel as well as the now approved WMO contrast threshold of 0.05 (see Table 5). Figure 15b also shows the significant threshold value of $0.5 \mathrm{n} \mathrm{mi}$ $(\approx 1 \mathrm{~km})$ used for helicopter operations.

The newer offshore datasets for 2016, 2017, and 2018 presented here are larger than the dataset used by Kunkel (1984). The newer data were obtained in a marine, or open-ocean environment, while those of Kunkel were more representative of a coastal environment, being $12 \mathrm{~km}$ inland on Cape Cod, Massachusetts. Kunkel used two Particle Measuring Systems (PMS) Forward Scatter Spectrometer Probes (FSSP-100) mounted at the 5- and 30-m levels. However, the fits to each dataset are comparable. Both the more recent data and that of Kunkel represent mainly advection fog.

\section{Suggestion for a new visibility prediction scheme}

As shown in section 3 [Eqs. (1)-(3)], if droplet concentration and cloud liquid water content are prognostic variables in a numerical weather prediction model, it is possible to calculate visibility due to liquid fog directly. Many present models predict cloud liquid water content. The difficult part is the prediction of droplet concentration. This would normally mean predicting the aerosol particle concentration and then assuming that some fraction acts as cloud condensation nuclei, which would lead to a prediction of droplet number concentration. The physics and chemistry of doing this correctly (see Pruppacher and Klett 1997) and with precision is not easy, although Wilkinson et al. (2013) made an attempt.

The data presented in Fig. 15 and the relationships between visibility, droplet concentration, and liquid water content in section 4 [Eqs. (1)-(3)] suggest a more pragmatic approach. If one assumes a droplet concentration of a certain value, then using the model-derived cloud liquid water content and Eqs. (1)-(3), visibility can be calculated directly. Figure 16 shows how the relationships assuming droplet concentrations of 50,100, and $150 \mathrm{~cm}^{-3}$ compare with the fits of Fig. $15 \mathrm{~b}$ and Table 5. The comparison of the theoretical curves with the observations is reasonable, although somewhat lower visibilities are predicted using Eqs. (1)-(3) at low liquid water contents than the observations suggest. Using such a scheme based on Eqs. (1)-(3) would be physically realistic and not subject to the difficulties of the many diagnostic parameterizations that now exist. Figure 10 shows how observations can be used to select a typical droplet number concentration for the geographical area where the visibility prediction is being made.

\section{Modeling and verification}

The new modeling prediction scheme was tested and compared with other numerical weather prediction 
July - August 2016 LWC $>0.005 \mathrm{~g} \mathrm{~m}^{-3}$; Wind $180-270^{\circ}$

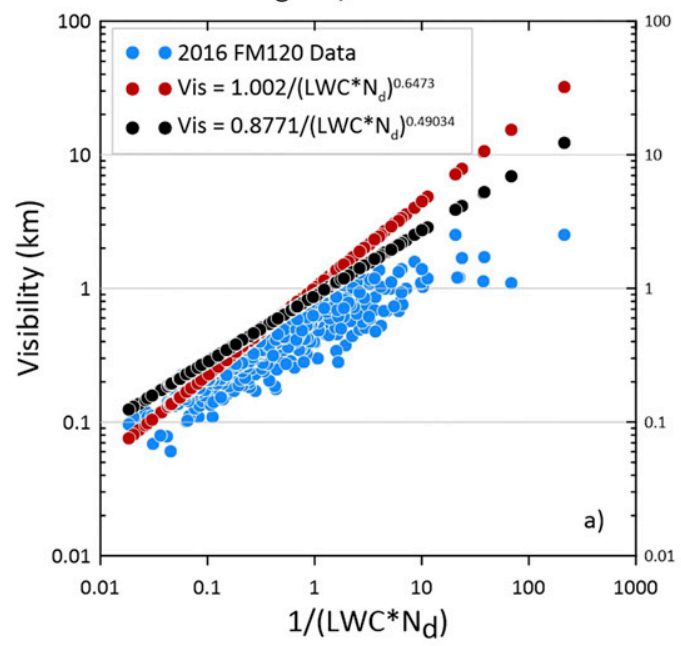

June - July 2018 LWC $>0.005 \mathrm{~g} \mathrm{~m}^{-3}$; Wind $180-270^{\circ}$

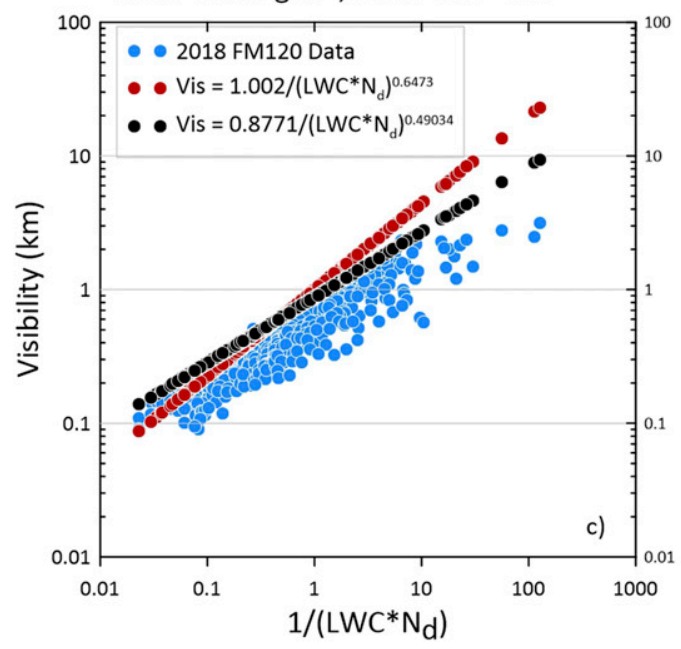

schemes for visibility during the period 1 June 2018-31 August 2018. These results should be considered preliminary as the assessments are ongoing. Given that helicopters, by Transport Canada regulation, cannot land offshore when visibility is less than $0.5 \mathrm{n} \mathrm{mi}$, it is useful to validate prediction systems using a categorical system of fog (visibility less than $0.5 \mathrm{n} \mathrm{mi}$ ) versus no-fog (visibility greater than or equal to $0.5 \mathrm{n} \mathrm{mi}$ ). The models were verified using observations made by the weather observer on Offshore Installation 1, who had access to a visibility sensor and to surface-based reference points, such as vessels and buoys.

The validation was performed based on a $2 \times 2$ contingency table (Table 6). The numbers in the table are counts of the numbers of events that were forecast to fall within a category. The category of "fog" was defined as visibility less than $0.5 \mathrm{n} \mathrm{mi}$. The category of "no-fog" was

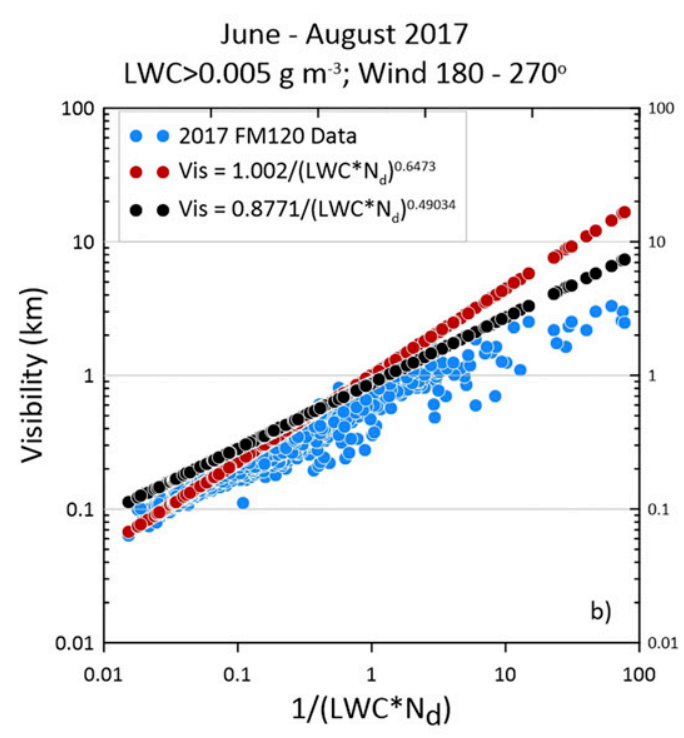

FIG. 14. Visibility vs $1 /\left(\mathrm{LWC} \times N_{d}\right)$ for the (a) 2016 , (b) 2017, and (c) 2018 Fog Monitor data (blue points) and the parameterizations of Gultepe et al. (2006, 2010). Gultepe et al. (2006) is represented by the red points, and Gultepe et al. (2010) is represented by the black points.

defined as visibility greater than or equal to $0.5 \mathrm{n}$ mi. For example, "hits" was the count of events when visibility was forecast to be less than $0.5 \mathrm{n} \mathrm{mi}$ and the observed visibility was less than $0.5 \mathrm{n}$ mi.

From the contingency table, it is possible to calculate some metrics. The ones used in the present study are listed below:

Probability of detection (POD; perfect score is 1.0):

$$
\text { POD }=\frac{\text { hits }}{\text { hits }+ \text { misses }} .
$$

False alarm rate or probability of false detection (FAR; perfect score is 0.0 ):

$$
\mathrm{FAR}=\frac{\text { false alarms }}{\text { hits }+ \text { false alarms }} .
$$



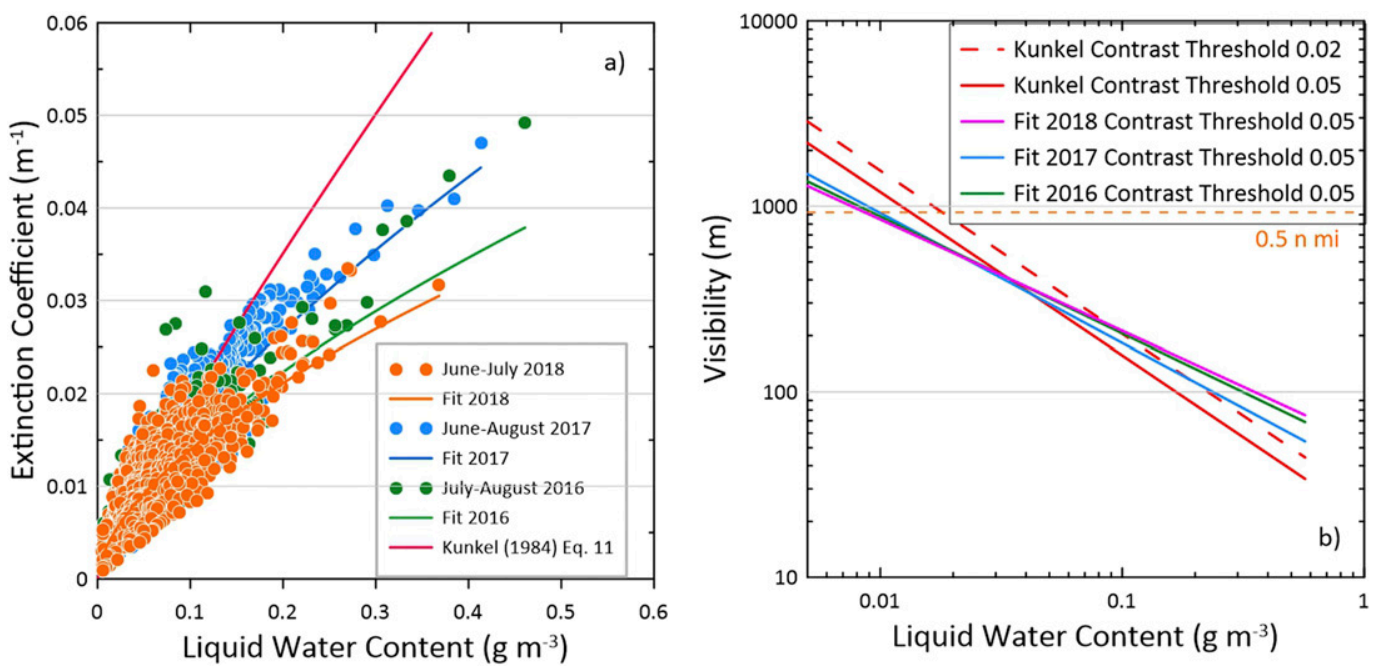

FIG. 15. (a) Fog Monitor (FM-120) 10-min extinction measurements for 2016, 2017, and 2018 plotted against liquid water content (LWC) for $\mathrm{LWC}>0.018 \mathrm{~g} \mathrm{~m}^{-3}$ and wind direction $180^{\circ}-270^{\circ}$. Also shown is the Kunkel (1984) fit [Kunkel's Eq. (11)]. (b) Using a contrast threshold of 0.05 and 0.02 as used by Kunkel, the visibility plotted against LWC for the fits in Table $5\left(\mathrm{LWC}>0.005 \mathrm{~g} \mathrm{~m}^{-3}\right)$. The $0.5 \mathrm{n} \mathrm{mi}$ threshold for helicopter approaches to offshore installations is indicated in (b).

Bias score (BIAS; perfect score 1.0):

$$
\text { BIAS }=\frac{\text { hits }+ \text { false alarms }}{\text { hits }+ \text { misses }}
$$

Heidke skill score (HSS; perfect score 1.0; no skill 0.0):

$$
\text { HSS }=\frac{(\text { hits }+ \text { correct negatives })-(\text { expected correct })_{\text {random }}}{\text { total }-(\text { expected correct })_{\text {random }}}
$$

where

$$
\begin{aligned}
& (\text { expected correct })_{\text {random }} \\
& =\frac{1}{\text { total }} \times[(\text { hits }+ \text { misses }) \times(\text { hits }+ \text { false alarms }) \\
& \quad+(\text { correct negatives }+ \text { misses }) \\
& \quad \times(\text { correct negatives }+ \text { false alarms })]
\end{aligned}
$$

Table 7 shows the results of the verification using 1) the Boudala et al. (2012) scheme, 2) the Stoelinga and Warner (1999) method, 3) the new scheme described in section 5 assuming a droplet concentration of $80 \mathrm{~cm}^{-3}$, and 4) the "native" method used in the model itself. These schemes are labeled as 1) BDEA, 2) STWA, 3) WOOD, and 4) NATV. Only two models are used in Table 7; the European Centre for Medium-Range Weather Forecasts (ECMWF) and the NOAA GFS global models, Forecasts produced by experienced operational forecasters and labeled as FORECAST were also prepared using all the available information and this product is compared with the direct model output.

Several observations can be made from Table 7 . The manually, or human, produced FORECAST is the best prediction method for the 0-6-h time frame based on the HSS. The ECMWF BDEA scheme has the next best score in this 0-6-h time frame and does the best in the 6-18- and 18-48-h time frames. Although other models were tested, this is the main reason this model/scheme combination was included in this analysis, because it did well in the fog/no-fog verifications. The verification for other models tested will be left to future papers. Unfortunately, STWA or WOOD could not be evaluated using ECMWF because the accessible products for ECMWF do not include cloud liquid water content, which is essential for these methods. The GFS BDEA and GFS WOOD methods seem to do well, but not as well as the ECMWF BDEA or FORECAST (Table 7). The GFS STWA and GFS NATV rank the lowest in this verification test. The GFS NATV scheme is based on Stoelinga and Warner (1999) so it is somewhat surprising that GFS STWA and GFS NATV have different scores. The GFS model output, available from Internet sources, was modified to produce GFS STWA, whereas the GFS NATV forecasts came directly from NOAA. There are probably subtle differences, but these are not known to the authors.

Figure 13 shows that the Boudala et al. (2012) or BDEA scheme is not physically realistic because, although their 
TABLE 5. Fits to the FM-120 data for 2016, 2017, and 2018 in Fig. 15a. The extinction coefficient $\beta$ is shown as a function of liquid water content (LWC), in a similar format to Kunkel (1984). The number of points, which represent 10 min for the 2016-18 data, and the total number of observation hours are shown.

\begin{tabular}{|c|c|c|c|c|}
\hline Year & Fit: $\beta$ vs LWC & LWC limit $\left(\mathrm{g} \mathrm{m}^{-3}\right)$ & Points & Hours \\
\hline 2016 & $\beta=0.063 \mathrm{LWC}^{0.64}$ & $>0.018$ & 775 & 129 \\
\hline 2016 & $\beta=0.062 \mathrm{LWC}^{0.63}$ & $>0.005$ & 858 & 143 \\
\hline 2017 & $\beta=0.080 \mathrm{LWC}^{0.69}$ & $>0.018$ & 961 & 160 \\
\hline 2017 & $\beta=0.082 \mathrm{LWC}^{0.70}$ & $>0.005$ & 1056 & 176 \\
\hline 2018 & $\beta=0.044 \mathrm{LWC}^{0.51}$ & $>0.018$ & 1420 & 237 \\
\hline 2018 & $\beta=0.056 \mathrm{LWC}^{0.60}$ & $>0.005$ & 1543 & 257 \\
\hline Kunkel (1984) & $\beta=0.144 \mathrm{LWC}^{0.88}$ & $>0.018$ & 1400 & 90 \\
\hline
\end{tabular}

parameterization predicts visibility changes with $\mathrm{RH}$, this does not appear to happen offshore with RH staying near $100 \%$ when fog is present. As mentioned above, Korolev and Isaac (2006) theoretically found that when liquid drops are present the air quickly becomes saturated with respect to water $(\mathrm{RH}=100 \%)$. But the BDEA scheme scores well in the categorical tests using the ECMWF and GFS models. Perhaps these models simulate RH better than cloud liquid water content, which is required for the STWA or WOOD methods, or the model $\mathrm{RH}$ prediction gives a better discrimination between fog and no-fog. The difference in the ability of the ECMWF and GFS models to forecast the atmosphere is probably the reason for any differences between ECMWF BDEA and GFS BDEA.

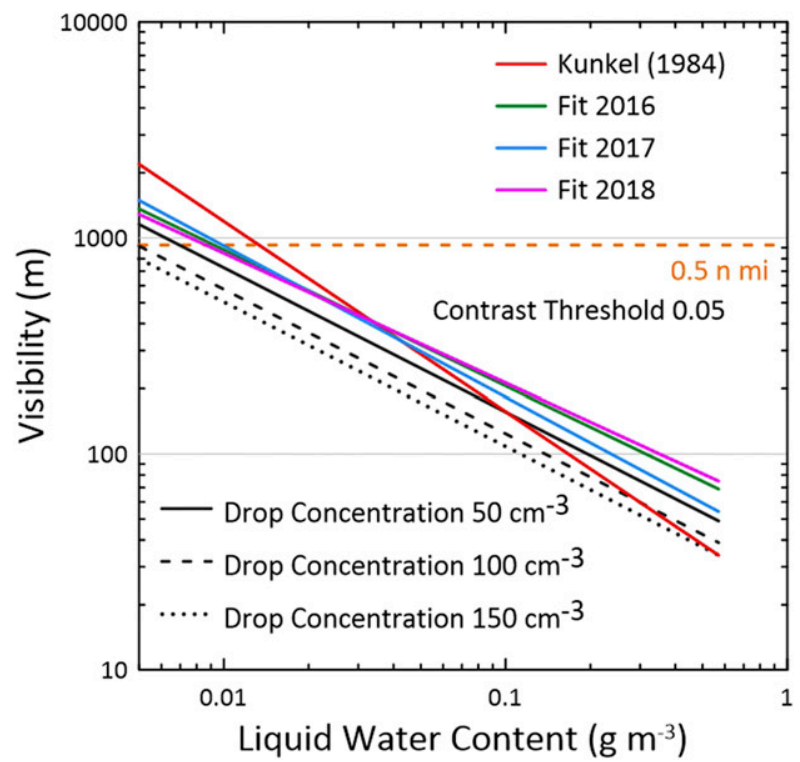

FIG. 16. Visibility vs liquid water content with fits to the 2016, 2017, and 2018 data, the Kunkel (1984) work, and lines drawn using Eq. (4) with drop concentrations of 50,100, and $150 \mathrm{~cm}^{-3}$. A contrast threshold of 0.05 is used for all lines. The $0.5 \mathrm{n} \mathrm{mi}$ threshold for helicopter approaches to offshore installations is indicated.

\section{Summary}

Some conclusions can be reached for this study and are listed below:

1) Warm advection fog occurs frequently offshore of Newfoundland and Labrador with visibilities less than $0.5 \mathrm{n} \mathrm{mi}$ or $\approx 1 \mathrm{~km}$ occurring $45 \%$ of the time during July (Fig. 3). When fog occurs, winds are usually from the southwest coming from the warm waters of the Gulf Stream over the colder waters of the Labrador Current-influenced Grand Banks (Figs. 3 and 4, Table 4).

2) There is no observed diurnal variation in marine fog frequency at this offshore location (Table 1), which is logical considering that there is no diurnal variation in temperature, dewpoint, $\mathrm{RH}$, winds, and sea surface temperature (Tables 2-4). Fog occurs frequently with relatively high wind speeds (Table 4 and Figs. 3 and 4). These are very different characteristics as compared to radiation fog or coastal fog.

3) Marine visibility is closely linked to the sea surface temperature, with lower visibilities occurring when the difference between air temperature or dewpoint temperature and sea surface temperature is greater (Fig. 6a). This is linked to the warm advection fog formation mechanism.

4) The Fog Monitor measurements show the range of values of fog droplet number concentrations and fog liquid water content. Median values of droplet concentrations were 75,97 , and $69 \mathrm{~cm}^{-3}$ when winds were from $180^{\circ}$ to $270^{\circ}$ in 2016,2017 , and 2018 , respectively. The corresponding median liquid water

TABLE 6. Contingency table used for forecast evaluation.

\begin{tabular}{lllll}
\hline \hline \multirow{2}{*}{} & \multicolumn{3}{c}{ Observed } \\
\cline { 2 - 4 } & & \multicolumn{2}{c}{ Yes } & \multicolumn{2}{c}{ No } \\
\hline Forecast & Yes & Hits & False alarms & Forecast yes \\
& No & Misses & Correct negatives & Forecast no \\
& & Observed yes & Observed no & Total \\
\hline
\end{tabular}


TABLE 7. Categorical model validation (BIAS, POD, FAR, and HSS) for 0-6-, 6-18-, and 18-48-h lead times. Here ECM refers to ECMWF.

\begin{tabular}{|c|c|c|c|c|c|c|c|}
\hline BIAS & Source & POD & Source & FAR & Source & HSS & Source \\
\hline \multicolumn{8}{|c|}{ Categorical validation: 0-6-h lead times } \\
\hline 0.024 & FORECAST & 0.89 & FORECAST & 0.09 & GFS_BDEA & 0.76 & FORECAST \\
\hline 0.059 & ECM_BDEA & 0.81 & ECM_BDEA & 0.13 & FORECAST & 0.72 & ECM_BDEA \\
\hline 0.209 & GFS_WOOD & 0.65 & GFS_WOOD & 0.14 & ECM_BDEA & 0.54 & GFS_BDEA \\
\hline 0.283 & GFS_STWA & 0.57 & GFS_STWA & 0.17 & GFS_NATV & 0.5 & GFS_WOOD \\
\hline 0.392 & GFS_BDEA & 0.55 & GFS_BDEA & 0.18 & GFS_WOOD & 0.47 & GFS_STWA \\
\hline 0.964 & GFS_NATV & 0.03 & GFS_NATV & 0.21 & GFS_STWA & 0.04 & GFS_NATV \\
\hline \multicolumn{8}{|c|}{ Categorical validation: $6-18$-h lead times } \\
\hline 0.051 & FORECAST & 0.82 & FORECAST & 0.1 & GFS_BDEA & 0.71 & ECM_BDEA \\
\hline 0.076 & ECM_BDEA & 0.79 & ECM_BDEA & 0.11 & GFS_NATV & 0.65 & FORECAST \\
\hline 0.183 & GFS_WOOD & 0.67 & GFS_WOOD & 0.15 & ECM_BDEA & 0.58 & GFS_BDEA \\
\hline 0.258 & GFS_STWA & 0.6 & GFS_BDEA & 0.16 & FORECAST & 0.53 & GFS_WOOD \\
\hline 0.338 & GFS_BDEA & 0.57 & GFS_STWA & 0.18 & GFS_WOOD & 0.47 & GFS_STWA \\
\hline 0.981 & GFS_NATV & 0.02 & GFS_NATV & 0.24 & GFS_STWA & 0.02 & GFS_NATV \\
\hline \multicolumn{8}{|c|}{ Categorical validation:18-48-h lead times } \\
\hline 0.04 & FORECAST & 0.79 & ECM_BDEA & 0.12 & GFS_BDEA & 0.67 & ECM_BDEA \\
\hline 0.048 & ECM_BDEA & 0.78 & FORËCAST & 0.18 & GFS_NATV & 0.62 & GFS_BDEA \\
\hline 0.112 & GFS_STWA & 0.7 & GFS_WOOD & 0.19 & GFS_WOOD & 0.59 & FORECAST \\
\hline 0.138 & GFS_WOOD & 0.63 & GFS_BDEA & 0.2 & FORECAST & 0.54 & GFS_WOOD \\
\hline 0.282 & GFS_BDEA & 0.61 & GFS_STWA & 0.21 & ECM_BDEA & 0.45 & GFS_STWA \\
\hline 0.95 & GFS_NATV & 0.05 & GFS_NATV & 0.33 & GFS_STWA & 0.06 & GFS_NATV \\
\hline
\end{tabular}

contents were $0.049,0.057$, and $0.057 \mathrm{~g} \mathrm{~m}^{-3}$ for 2016 , 2017, and 2018, respectively.

5) The Fog Monitor measurements show bimodal size distributions with peaks near 6 and $25-30 \mu \mathrm{m}$. The larger droplet sizes often contain more liquid water content, especially with higher total liquid water contents (Fig. 12).

6) When fog occurs, the relative humidity values $(\mathrm{RH})$ tend to be very close to $100 \%$, making RH difficult to use as a predictor (Fig. 13). However, preliminary forecast model verifications show that using a $\mathrm{RH}-$ based parameterization, such as that proposed by Boudala et al. (2012), can be effective for fog versus no-fog discrimination.

7) The Fog Monitor measurements made offshore Newfoundland and Labrador show a similar relationship between extinction and liquid water content found by Kunkel (1984) in a coastal environment, and used in the Stoelinga and Warner (1999) forecast scheme (Fig. 16).

8) A new, more physically realistic, method of forecasting visibility using prognostically predicted liquid water content and an assumed fog droplet concentration has been proposed. This technique should be easier to implement, but it requires accurate liquid water content predictions within the model boundary layer.

9) This new scheme was evaluated using the NOAA Global Prediction System (GFS) model and shows reasonable skill (Table 7). Assessment of this scheme is ongoing.
The climatology and characteristics of marine fog shown in the paper are quite unique and hopefully more studies will be undertaken to show if results are similar in other geographies.

Acknowledgments. Andrew Peddle and Niaz Mohammed of Wood Environment and Infrastructure Solutions provided vital support for data collection and data analysis.

\section{REFERENCES}

American Meteorological Society, 2018: Fog. Glossary of Meteorology, http://glossary.ametsoc.org/wiki/Fog.

Bergot, T., and D. Guedalia, 1994: Numerical forecasting of radiation fog. Part I: Numerical model and sensitivity tests. Mon. Wea. Rev., 122, 1218-1230, https://doi.org/10.1175/ 1520-0493(1994)122<1218:NFORFP > 2.0.CO;2.

Bott, A., and T. Trautmann, 2002: PAFOG-A new efficient forecast model of radiation fog and low-level stratiform clouds. Atmos. Res., 64, 191-203, https://doi.org/10.1016/ S0169-8095(02)00091-1.

Boudala, F. S., G. A. Isaac, R. Crawford, and J. Reid, 2012: Parameterization of runway visual range as a function of visibility: Implications for numerical weather prediction models. J. Atmos. Oceanic Technol., 29,177-191, https://doi.org/10.1175/ JTECH-D-11-00021.1.

Brodrick, C. T., 1907: Fog on the Newfoundland Banks. Mon. Wea. Rev., 35, 76-78, https://doi.org/10.1175/1520-0493(1907) $35<76 \mathrm{~b}:$ FOTNB $>2.0 . \mathrm{CO} ; 2$.

Bullock, T., G. A. Isaac, J. Beale, and T. Hauser, 2016: Improvement of visibility and severe sea state forecasting on the Grand Banks of Newfoundland and Labrador. Arctic Technology Conf., St. John's, Newfoundland and Labrador, Canada, 
Offshore Technology Conference Doc. OTC-27406-MS, https://doi.org/10.4043/27406-MS.

Burrows, W. R., and G. Toth, 2011: Automated fog and stratus forecasts from the Canadian RDPS operational NWP Model. 24th Conf. on Weather Analysis and Forecasting, Seattle, WA, Amer. Meteor. Soc., 14A.5, https://ams.confex.com/ams/ 91Annual/webprogram/Paper181141.html.

Cho, Y.-K., M.-O. Kim, and B.-C. Kim, 2000: Sea fog around the Korean Peninsula. J. Appl. Meteor., 39, 2473-2479, https:// doi.org/10.1175/1520-0450(2000)039<2473:SFATKP >2.0.CO;2.

Dorman, C. E., J. Mejia, D. Koračin, and D. McEvoy, 2017: Worldwide marine fog occurrence and climatology. Marine Fog: Challenges and Advancements in Observations, Modeling, and Forecasting, D. Koračin and C. E. Dorman, Eds., Springer, $7-152$.

Eldridge, R. G., 1966: Haze and fog aerosol distributions. J. Atmos. Sci., 23, 605-613, https://doi.org/10.1175/1520-0469(1966) 023<0605:HAFAD $>2.0 . \mathrm{CO} ; 2$.

_- 1971: The relationship between visibility and liquid water content in fog. J. Atmos. Sci., 28, 1183-1186, https://doi.org/ 10.1175/1520-0469(1971)028<1183:TRBVAL > 2.0.CO;2.

Environment and Climate Change Canada, 2017: MANMAR: Manual of Marine Weather Observations. Environment and Climate Change Canada, 241 pp., https://www.canada.ca/en/ environment-climate-change/services/weather-manualsdocumentation/marine-observations.html.

Findlater, J., W. T. Roach, and B. C. McHugh, 1989: The haar of north-east Scotland. Quart. J. Roy. Meteor. Soc., 115, 581-608, https://doi.org/10.1002/qj.49711548709.

Gao, S., H. Lin, B. Shen, and G. Fu, 2007: A heavy sea fog event over the Yellow Sea in March 2005: Analysis and numerical modeling. Adv. Atmos. Sci., 24, 65-81, https://doi.org/10.1007/ s00376-007-0065-2.

Gultepe, I., and J. A. Milbrandt, 2010: Probabilistic parameterizations of visibility using observations of rain precipitation rate, relative humidity, and visibility. J. Appl. Meteor. Climatol., 49, 36-46, https://doi.org/10.1175/2009JAMC1927.1.

- M. D. Müller, and Z. Boybeyi, 2006: A new visibility parameterization for warm-fog applications in numerical weather prediction models. J. Appl. Meteor. Climatol., 45, 1469-1480, https://doi.org/10.1175/JAM2423.1.

, and Coauthors, 2009: The fog remote sensing and modeling field project. Bull. Amer. Meteor. Soc., 90, 341-360, https:// doi.org/10.1175/2008BAMS2354.1.

, J. A. Milbrandt, and Z. Binbin, 2010: Visibility parameterization for forecasting model applications. Fifth Int. Conf. on Fog, Fog Collection and Dew, Münster, Germany, University of Münster, Climatology Working Group, FOGDEW2010112, https://meetingorganizer.copernicus.org/FOGDEW2010/ FOGDEW2010-112.pdf.

Guo, J., P. Li, G. Fu, W. Zhang, S. Gao, and S. Zhang, 2015: The structure and formation mechanism of a sea fog event over the Yellow Sea. J. Ocean Univ. China, 14, 27-37, https://doi.org/ 10.1007/s11802-015-2466-7.

Hansen, B., 2007: A fuzzy logic-based analog forecasting system for ceiling and visibility. Wea. Forecasting, 22, 1319-1330, https:// doi.org/10.1175/2007WAF2006017.1.

Houghton, H. G., 1939: On the relation between visibility and the constitution of clouds and fog. J. Aeronaut. Sci., 6, 408-411, https://doi.org/10.2514/8.917.

Huang, H., H. Liu, W. Jiang, J. Huang, and W. Mao, 2011: Characteristics of the boundary layer structure of sea fog on the coast of southern China. Adv. Atmos. Sci., 28, 1377-1389, https://doi.org/10.1007/s00376-011-0191-8.

,$- \ldots$, J. Huang, W. Mao, and X. Bi, 2015: Atmospheric boundary layer structure and turbulence during sea fog on the southern China coast. Mon. Wea. Rev., 143, 1907-1923, https:// doi.org/10.1175/MWR-D-14-00207.1.

Kim, C. K., and S. S. Yum, 2010: Local meteorological and synoptic characteristics of fogs formed over Incheon Internationa Airport in the west coast of Korea. Adv. Atmos. Sci., 27, 761-776, https://doi.org/10.1007/s00376-009-9090-7.

- , and 2012: A numerical study of sea-fog formation over the cold sea surface using a one-dimensional turbulence model coupled with the Weather Research and Forecasting Model. Bound.-Layer Meteor., 143, 481-505, https://doi.org/10.1007/ s10546-012-9706-9.

Koračin, D., 2017: Modeling and forecasting marine fog. Marine Fog: Challenges and Advancements in Observations, Modeling, and Forecasting, D. Koračin and C. Dorman, Eds., Springer, 425-475.

Korolev, A. V., and G. A. Isaac, 2006: Relative humidity in liquid, mixed phase, and ice clouds. J. Atmos. Sci., 63, 2865-2880, https://doi.org/10.1175/JAS3784.1.

$\longrightarrow,-$ I. P. Mazin, and H. W. Barker, 2001: Microphysical properties of continental clouds from in situ measurements. Quart. J. Roy. Meteor. Soc., 127, 2117-2151, https://doi.org/ 10.1002/QJ.49712757614.

Koschmieder, H., 1924: Théorie der horizontalen Sichweite. Beitr. Freien Atmos., 12, 171-181.

Kunkel, A., 1984: Parameterization of droplet terminal velocity and extinction coefficient in fog models. J. Climate Appl. Meteor., 23, 34-41, https://doi.org/10.1175/1520-0450(1984) 023<0034:PODTVA $>2.0$.CO;2.

Leipper, D. F., 1994: Fog on the U.S. West Coast: A review. Bull. Amer. Meteor. Soc., 75, 229-240, https://doi.org/10.1175/ 1520-0477(1994)075<0229:FOTUWC > 2.0.CO;2.

Lewis, J. M., D. Koračin, and K. T. Redmond, 2004: Sea fog research in the United Kingdom and United States, a historical essay including outlook. Bull. Amer. Meteor. Soc., 85, 395-408, https://doi.org/10.1175/BAMS-85-3-395.

Marcet, W., 1889: On fogs. Quart. J. Roy. Meteor. Soc., 15, 59-72, https://doi.org/10.1002/qj.4970157001.

Osborne, A. H., 1976: Techniques for the prediction of sea fog over the Scotian Shelf. Environment Canada Rep. TEC-825, 18 pp

Pilié, R. J., E. J. Mack, C. W. Rogers, U. Katz, and W. C. Kocmond, 1979: The formation of marine fog and the development of fog-stratus systems along the California Coast. J. Appl. Meteor., 18, 1275-1286, https://doi.org/10.1175/1520-0450(1979) 018<1275:TFOMFA $>2.0 . \mathrm{CO} ; 2$.

Pinnick, R. G., D. L. Hoihjelle, G. Fernandez, E. B. Stenmark, J. D. Lindberg, G. B. Hoidale, and S. G. Jennings, 1978: Vertical structure in atmospheric fog and haze and its effect on visible and infrared extinction. J. Atmos. Sci., 35, 2020-2032, https://doi.org/ 10.1175/1520-0469(1978)035<2020:VSIAFA >2.0.CO;2.

Pruppacher, H. R., and J. D. Klett, 1997: Microphysics of Clouds and Precipitation. Kluwer Academic Publishers, 954 pp.

Rogers, C. W., 1989: Investigation of North Atlantic fog and development of a marine fog forecast system. Naval Environmental Prediction Research Facility Contractor Rep. CR 89-11, 59 pp.

Scoresby, L., 1822: Observations on the impregnation of wood with sea-water, and on the fog of the Polar Seas. Edinb. Philos. J., 6, 115-118.

Scott R. H., 1890: Elementary Meteorology. Kegan Paul Trench Trubner And Co. Ltd., 410 pp. 
Spiegel, J. K., P. Zieger, N. Bukowiecki, E. Hammer, E. Weingartner, and W. Eugster, 2012: Evaluating the capabilities and uncertainties of droplet measurements for the fog droplet spectrometer (FM-100). Atmos. Meas. Tech., 5, 2237-2260, https://doi.org/ 10.5194/amt-5-2237-2012.

Stoelinga, M. T., and T. T. Warner, 1999: Nonhydrostatic, mesobeta-scale model simulations of cloud ceiling and visibility for an East Coast winter precipitation event. J. Appl. Meteor., 38, 385-404, https://doi.org/10.1175/1520-0450(1999) $038<0385$ :NMSMSO $>2.0 . \mathrm{CO} ; 2$.

Tardif, R., and R. M. Rasmussen, 2007: Event-based climatology and typology of fog in the New York City region. J. Appl. Meteor. Climatol., 46, 1141-1168, https://doi.org/10.1175/JAM2516.1.

Taylor, G. I., 1915: Eddy motion in the atmosphere. Philos. Trans. Roy. Soc. London, A215, 1-26, https://doi.org/10.1098/rsta.1915.0001.

_ 1917: The formation of fog and mist. Quart. J. Roy. Meteor. Soc., 43, 241-268, https://doi.org/10.1002/qj.49704318302.

Tomasi, C., and F. Tampieri, 1976: Features of the proportionality coefficient in the relationship between visibility and liquid water content in haze and fog. Atmosphere, 14, 61-76, https:// doi.org/10.1080/00046973.1976.9648403.

Wilkinson, J. M., A. N. F. Porson, F. J. Bornemann, M. Weeks, P. R. Field, and A. P. Lock, 2013: Improved microphysical parametrization of drizzle and fog for operational forecasting using the Met Office Unified Model. Quart. J. Roy. Meteor. Soc., 139, 488-500, https://doi.org/10.1002/ qj.1975.

Willett,H. C., 1928: Fog and haze, their causes, distribution, and forecasting. Mon. Wea. Rev., 56, 435-468, https://doi.org/ 10.1175/1520-0493(1928)56<435:FAHTCD>2.0.CO;2.

Zhang, S.-P., S.-P. Xie, Q.-Y. Liu, Y.-Q. Yang, X.-G. Wang, and Z.-P. Ren, 2009: Seasonal variations of Yellow Sea fog: Observations and mechanisms. J. Climate, 22, 6758-6772, https://doi.org/10.1175/2009JCLI2806.1.

Zhao, L. J., S. J. Niu, Y. Zhang, and F. Xu, 2013: Microphysical characteristics of sea fog over the east coast of Leizhou Peninsula, China. Adv. Atmos. Sci., 30, 1154-1172, https:// doi.org/10.1007/s00376-012-1266-x. 